\title{
Experimental and Simulation Study of Adsorption in Postcombustion Conditions Using a Microporous Biochar. 2. $\mathrm{H}_{2} \mathrm{O}, \mathrm{CO}_{2}$, and $\mathrm{N}_{2}$ Adsorption
}

\author{
Marta G. Plaza, Inés Durán, Nausika Querejeta, Fernando Rubiera, and Covadonga Pevida* \\ Instituto Nacional del Carbón, INCAR-CSIC, Apartado 73, 33080 Oviedo, Spain
}

Supporting Information

\begin{abstract}
The adsorption behavior of humid mixtures that are representative of postcombustion conditions on a microporous biochar was evaluated. The adsorption isotherms of $\mathrm{H}_{2} \mathrm{O}_{\text {(v) }}$ were measured at 30,50 , and $70{ }^{\circ} \mathrm{C}$ up to the saturation pressure and fitted to the extended Cooperative Multimolecular Sorption (CMMS) model. Dynamic experiments were carried out in a fixed-bed adsorption unit with mixtures of $\mathrm{N}_{2}, \mathrm{CO}_{2}$, and $\mathrm{H}_{2} \mathrm{O}_{(\mathrm{v}}$. Experimental results indicate that $\mathrm{H}_{2} \mathrm{O}$ is little affected by $\mathrm{CO}_{2}$ adsorption. On the other hand, the $\mathrm{CO}_{2}$ adsorption capacity can be reduced by the
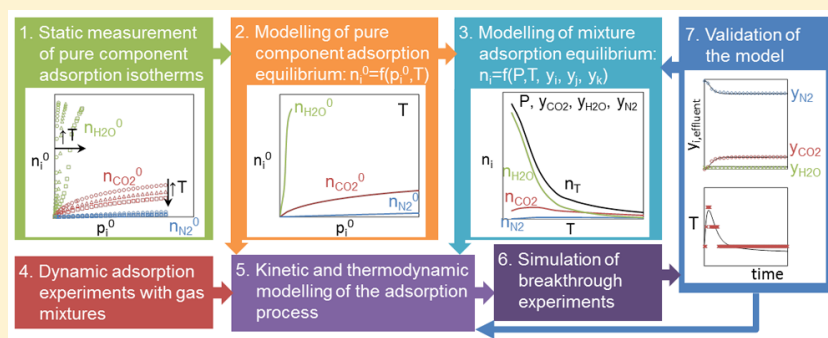
adsorption of $\mathrm{H}_{2} \mathrm{O}$. The extent of this reduction is dependent on the amount of $\mathrm{H}_{2} \mathrm{O}$ adsorbed, which, in turn, is strongly dependent on the relative humidity of the gas phase and the adsorption time. A dynamic fixed-bed adsorption model that makes use of Ideal Adsorbed Solution (IAS) theory has been shown to be adequate to describe the adsorption behavior of $\mathrm{CO}_{2}$ from the ternary mixtures in the full range of conditions evaluated.
\end{abstract}

\section{INTRODUCTION}

Several studies have assessed the coadsorption of $\mathrm{CO}_{2}$ and $\mathrm{H}_{2} \mathrm{O}$ from the perspective of air separation, that is, in the lowconcentration range. Shen and Worek ${ }^{1}$ studied the coadsorption of $\mathrm{CO}_{2}$ and $\mathrm{H}_{2} \mathrm{O}$ on BPL activated carbon, silica gel, and zeolite $13 \mathrm{X}$ molecular sieve, by using a linear isotherm to represent $\mathrm{CO}_{2}$ adsorption data up to $1100 \mathrm{ppm}$ and the Dubinin-Polanyi equation to represent $\mathrm{H}_{2} \mathrm{O}$ adsorption for a relative humidity $(\mathrm{RH})$ of $30 \%$. They reported a reduction of $<4 \%$ in the adsorption capacity of $\mathrm{H}_{2} \mathrm{O}$ in the presence of $\mathrm{CO}_{2}$, compared to the pure component capacity for BPL, $5 \%$ for the silica gel, and $10 \%$ for zeolite $13 \mathrm{X}$, and a reduction of $>35 \%$ in the case of $\mathrm{CO}_{2}$ for the activated carbon, 59\% for the silica gel, and $75 \%$ for the zeolite $13 \mathrm{X}$. Rege and $\mathrm{Yang}^{2}$ studied the adsorption of trace levels of $\mathrm{CO}_{2}$ and $\mathrm{H}_{2} \mathrm{O}$ in an inert gas on two adsorbents $-\gamma-\mathrm{Al}_{2} \mathrm{O}_{3}$ and zeolite $13 \mathrm{X}$ - and concluded that the amount of $\mathrm{CO}_{2}$ adsorbed was enhanced at very low partial pressures in the presence of trace amounts of $\mathrm{H}_{2} \mathrm{O}$, although that enhancement progressively disappeared as the sorbate partial pressure increased. These authors also fitted the experimentally measured mixture adsorption data to the Doong-Yang model, which is used for predicting gas mixture adsorption equilibrium from pure component isotherms of Dubinin type, and to the Ideal Adsorbed Solution (IAS) theory, which makes use of the Dubinin-Astakhov equation as a basis, and they found that $\mathrm{H}_{2} \mathrm{O}$ loading was reasonably well-predicted by both models, although the Doong-Yang model gave a marginally better fit to the experimental mixture adsorption data. Bai and Yang ${ }^{3}$ compared the results of the Doong-Yang model obtained by Rege and Yang with a modification of the
Doong-Yang model for gas mixture adsorption using the Lewis relationship (Doong-Yang II model) and found that the original Doong-Yang model gave a marginally better fit to the $\mathrm{CO}_{2}-\mathrm{H}_{2} \mathrm{O}$ adsorption data in the low-pressure range.

The adsorption of $\mathrm{CO}_{2}$ in carbon capture applications constitutes a bulk separation, which greatly differs from the case of air purification. In the postcombustion $\mathrm{CO}_{2}$ capture scenario, the gas stream that must be decarbonized is mainly composed by $\mathrm{N}_{2}, \mathrm{O}_{2}, \mathrm{CO}_{2}$, and $\mathrm{H}_{2} \mathrm{O}$, with much lesser contents of $\mathrm{NO}_{x}$ and $\mathrm{SO}_{x}$. Most adsorbents are selective toward $\mathrm{CO}_{2}$ over $\mathrm{N}_{2}$ and $\mathrm{O}_{2}$, and the trace amounts of $\mathrm{SO}_{x}$ and $\mathrm{NO}_{x}$ are not expected to be a problem for physical adsorbents. ${ }^{4}$ On the other hand, $\mathrm{H}_{2} \mathrm{O}$ is strongly adsorbed by polar adsorbents, which means that a dehydrating unit must be installed prior to a zeolite-based adsorption unit. ${ }^{5-7}$ Even hydrophobic adsorbents such as carbons, which do not present a high affinity for $\mathrm{H}_{2} \mathrm{O}$, can adsorb significant amounts of water at the high $\mathrm{RH}$ value that is to be expected for the flue gas exiting a wet desulfurization unit. For this reason, it is imperative to gain insight into the influence of the coadsorption of $\mathrm{H}_{2} \mathrm{O}$ and $\mathrm{CO}_{2}$ under postcombustion conditions. $\mathrm{Li}$ et al. ${ }^{8}$ evaluated the effect of $\mathrm{H}_{2} \mathrm{O}$ adsorption on $\mathrm{CO}_{2}$ capture, using zeolite $13 \mathrm{X}$ as an adsorbent. They carried out breakthrough experiments with a feed stream containing $\sim 9 \% \mathrm{CO}_{2}$ and $3.5 \% \mathrm{H}_{2} \mathrm{O}$ at $30{ }^{\circ} \mathrm{C}$ and $115 \mathrm{kPa}$, which corresponds to an $\mathrm{RH}$ value of $95 \%$, and observed a profound roll-up in the breakthrough curve of $\mathrm{CO}_{2}$

Received: May 4, 2016

Accepted: May 31, 2016

Published: May 31, 2016 
and a large thermal wave of up to $100{ }^{\circ} \mathrm{C}$ produced by $\mathrm{H}_{2} \mathrm{O}$ adsorption. These authors reported a reduction in the equilibrium capacity of $\mathrm{H}_{2} \mathrm{O}$ of $14 \%$ and of $99 \%$ in the case of $\mathrm{CO}_{2}$ by the competitive coadsorption of $\mathrm{H}_{2} \mathrm{O}$. Jin and Firoozabadi ${ }^{9}$ studied the effect of water on carbon dioxide adsorption in clay minerals by Monte Carlo simulations. They concluded that $\mathrm{CO}_{2}$ adsorption in clay minerals is greatly reduced by water, because of the formation of a water adsorption layer on the hydrophilic clay surfaces, as $\mathrm{CO}_{2}$ and $\mathrm{H}_{2} \mathrm{O}$ adsorb in the same layer for pores of $1 \mathrm{~nm}$. While the reduction of $\mathrm{CO}_{2}$ adsorption capacity in hydrophilic inorganic adsorbents is drastic, the impact of $\mathrm{H}_{2} \mathrm{O}$ in hydrophobic carbon materials has been reported to be much lower. Rutherford ${ }^{10}$ studied the equilibrium of adsorption of $\mathrm{CO}_{2}$ over Takeda $5 \mathrm{~A}$ carbon molecular sieve that had been preadsorbed with $\mathrm{H}_{2} \mathrm{O}$. $\mathrm{He}$ found that the preadsorbed water caused significant exclusion of $\mathrm{CO}_{2}$ from the micropores, and proposed a quantitative bimodal model to describe the behavior observed. However, this model has an important drawback: it uses an empirical parameter, the fraction of carbon dioxide molecules residing outside the graphene microstructure, which must be evaluated from binary adsorption experiments. $\mathrm{Xu}$ et al. ${ }^{11}$ studied the effect of water vapor on $\mathrm{CO}_{2}$ capture over the temperature range of $25-60{ }^{\circ} \mathrm{C}$ using a coconut shell activated carbon, Acticarb GC1200, as the adsorbent. They used the simplified form of the extended Cooperative Multimolecular Sorption (CMMS) theory, originally developed by Malakhov and Volkov, ${ }^{12}$ and first proposed by Rutherford to describe the equilibrium of adsorption of $\mathrm{H}_{2} \mathrm{O}$ on microporous carbons. ${ }^{13}$ However, they did not consider the competitive adsorption between $\mathrm{CO}_{2}$ and $\mathrm{H}_{2} \mathrm{O}$. The simulation of a binary breakthrough curve of $\mathrm{CO}_{2}$ and $\mathrm{H}_{2} \mathrm{O}$ based on the pure component adsorption models satisfactorily reproduced the breakthrough time of the adsorbates, but failed to describe the full shape of the breakthrough curves and the temperature history of the adsorbent. Our research group previously addressed the adsorption of $\mathrm{CO}_{2}$ from humid and dry synthetic flue gas mixtures using microporous carbon adsorbents, ${ }^{14-16}$ and observed that the presence of $\mathrm{H}_{2} \mathrm{O}$ in the feed hardly influenced the breakthrough time of $\mathrm{CO}_{2}$. However, we also noted that the amount of $\mathrm{CO}_{2}$ adsorbed can be reduced in the long term by the coadsorption of $\mathrm{H}_{2} \mathrm{O} .{ }^{14}$ In this work, the coadsorption of $\mathrm{CO}_{2}$ and $\mathrm{H}_{2} \mathrm{O}$ is further addressed using experimental and simulation results. The equilibrium of adsorption of $\mathrm{H}_{2} \mathrm{O}$ was assessed using a static adsorption apparatus in the temperature range of $30-70{ }^{\circ} \mathrm{C}$. This technique provided reliable equilibrium data that were fitted to the extended CMMS theory in the simplified form proposed by Rutherford for the adsorption of $\mathrm{H}_{2} \mathrm{O}$ on microporous carbons. ${ }^{10}$ Ternary breakthrough curves were carried out using mixtures of $\mathrm{N}_{2}, \mathrm{CO}_{2}$, and $\mathrm{H}_{2} \mathrm{O}$, and these were compared to binary breakthrough curves carried out with $\mathrm{N}_{2}$ and $\mathrm{H}_{2} \mathrm{O}$ mixtures to evaluate the influence of $\mathrm{CO}_{2}$ on $\mathrm{H}_{2} \mathrm{O}$ adsorption departing from a fully regenerated adsorbent. The dynamic adsorption of the ternary $\mathrm{N}_{2} / \mathrm{H}_{2} \mathrm{O} / \mathrm{CO}_{2}$ mixture was also evaluated, departing from the adsorbent initially saturated with $\mathrm{H}_{2} \mathrm{O}$ and $\mathrm{N}_{2}$ at $\mathrm{RH}$ values between $9 \%$ and $95 \%$. The breakthough experiments were simulated using Aspen Adsorption V8.0. The mathematical model of the adsorption column is based on the mass, momentum and energy balances, kinetics and equilibrium of adsorption relations, and boundary and initial conditions. ${ }^{17-19}$ The IAS theory, ${ }^{20}$ which is based on the pure component adsorption models (i.e., the extended
CMMS model for the adsorption of $\mathrm{H}_{2} \mathrm{O}$ and the Toth model for the adsorption of $\mathrm{CO}_{2}$ and $\mathrm{N}_{2}$ ), was used to account for competitive adsorption. This model was previously validated for the binary adsorption of $\mathrm{CO}_{2} / \mathrm{N}_{2}$ mixtures on the same adsorbent under the same temperature, pressure, and feed composition range. ${ }^{19}$

\section{MATERIALS AND METHODS}

The adsorbent used in the present work is a biochar developed from olive stones by air oxidation (further details can be found elsewhere ${ }^{19,21}$ ).

Equilibrium of Adsorption of $\left.\mathrm{H}_{2} \mathrm{O}_{(} \mathbf{v}\right)$. The adsorption isotherms of $\mathrm{H}_{2} \mathrm{O}$ at 30,50 , and $70{ }^{\circ} \mathrm{C}$ were measured up to the corresponding saturation pressure using a sorption analyzer (Hydrosorb $1000 \mathrm{HT}$, Quantachrome). Prior to the adsorption measurements, the sample was outgassed overnight under vacuum at $100{ }^{\circ} \mathrm{C}$. During analysis, the temperature of the sample cell was controlled using a thermostatic bath circulator (Julabo).

Relatively simple adsorption models, such as the Toth equation, which has been shown to be adequate to describe the equilibrium of adsorption of pure $\mathrm{CO}_{2}$ and $\mathrm{N}_{2}$, ${ }^{19}$ fail to describe the equilibrium of adsorption of $\mathrm{H}_{2} \mathrm{O}$ on carbon adsorbents in the full $\mathrm{RH}$ range. To the authors' knowledge, only two models have been proposed that are useful for that purpose. The model proposed by Do, Junpirom, and Do (DJD) ${ }^{22}$ for the adsorption of water vapor on microporous carbons (which is a specific case of the most complete model later proposed by Horikawa and $\mathrm{Do}^{23}$ ) has been proven suitable to describe the equilibrium of adsorption (and desorption) of water vapor up to the saturation pressure on a similar biochar. ${ }^{16}$ The other adsorption model that has been found to be useful to describe the adsorption of $\mathrm{H}_{2} \mathrm{O}$ on microporous carbons in the entire relative pressure range is the extended CMMS isotherm first proposed to this end by Rutherford ${ }^{10,13}$ (see eq 1). This model treats the adsorption of water on microporous carbons as the contribution of two independent modes of adsorption: the adsorption on the carbon functional groups that can be described by the equation of Langmuir, and the adsorption of water in the micropores, which is described by a simplified form of the CMMS theory. In the micropores, the interaction of $\mathrm{H}_{2} \mathrm{O}$ with the carbon surface (the primary site) is followed by cooperative interaction of the adsorbed water molecules with other water molecules, promoting their adsorption on adjacent sites (side units of the primary site); secondary interactions, also considered in the CMMS theory, ${ }^{12}$ are not taken into consideration, because of limitations of space inside the micropores, thus reducing the CMMS equation to the Ising isotherm:

$$
n_{\mathrm{H}_{2} \mathrm{O}}=\frac{n_{\mathrm{L}} b_{\mathrm{L}} P}{1+b_{\mathrm{L}} P}+\frac{n_{\mathrm{s}} K_{0} P}{K_{0} P+w_{\text {Ising }}{ }^{2}}
$$

where $n_{\mathrm{H}_{2} \mathrm{O}}$ is the total amount of $\mathrm{H}_{2} \mathrm{O}$ adsorbed on the carbon, $n_{\mathrm{L}}$ the maximum adsorption capacity on the surface functional groups, $b_{\mathrm{L}}$ the Langmuir affinity constant for the interaction of water with the surface functional groups, $P$ the partial pressure of $\mathrm{H}_{2} \mathrm{O}, n_{\mathrm{s}}$ the saturation capacity for the adsorption of water in the micropores, and $K_{0}$ the equilibrium constant for the adsorption on the primary site. The term $w_{\text {Ising }}$ is given by eq 2 ,

$$
w_{\text {Ising }}=\frac{1}{2}\left[1-K_{1} P+\sqrt{\left(1-K_{1} P\right)^{2}+4 K_{0} P}\right]
$$


where $K_{1}$ is the equilibrium constant of adsorption on the side unit of the primary site.

The water adsorption capacity parameters $\left(n_{\mathrm{L}}\right.$ and $\left.n_{\mathrm{s}}\right)$ are assumed to be temperature-independent over the temperature range studied. ${ }^{10}$ The first term of eq 1 is the ordinary form of the Langmuir model, the affinity constant of which has a known temperature dependence, given by eq 3. A similar van't Hoff temperature dependence was assumed for the other equilibrium constants $\left(K_{0}\right.$ and $\left.K_{1}\right)$, as shown in eqs 4 and 5 , respectively, following the approach originally proposed by Rutherford: ${ }^{10}$

$$
\begin{aligned}
& b_{\mathrm{L}}(T)=b_{\mathrm{L}, T_{\text {ref }}} \exp \left[\frac{q_{\mathrm{L}}}{\mathrm{R} T_{\text {ref }}}\left(\frac{T_{\text {ref }}}{T}-1\right)\right] \\
& K_{0}(T)=K_{0, T_{\text {ref }}} \exp \left[\frac{q_{0}}{\mathrm{R} T_{\text {ref }}}\left(\frac{T_{\text {ref }}}{T}-1\right)\right] \\
& K_{1}(T)=K_{1, T_{\text {ref }}} \exp \left[\frac{q_{1}}{\mathrm{R} T_{\text {ref }}}\left(\frac{T_{\text {ref }}}{T}-1\right)\right]
\end{aligned}
$$

where $q_{\mathrm{L}}, q_{0}$, and $q_{1}$ are related to the enthalpy of adsorption on the surface functional groups, on the primary sites, and on the side units of the primary sites, respectively; $\mathrm{R}$ is the universal gas constant; and $T_{\text {ref }}$ is a reference temperature (here, taken as $303 \mathrm{~K})$. Parameters $n_{\mathrm{L}}, b_{\mathrm{L}, T_{\mathrm{ree}}} q_{\mathrm{L}}, n_{\mathrm{s}}, K_{0, T_{\mathrm{rep}}} q_{0}, K_{1, T_{\mathrm{rep}}}$ and $q_{1}$ were adjusted to minimize the mean squared error (MSE), which is calculated using eq 6 :

$$
\text { MSE }=\frac{\sum_{T}\left(\frac{\sum_{i=1}^{N_{\mathrm{A}}}\left(n_{\text {exp }}-n_{\text {calc }}\right)^{2}}{N_{\mathrm{A}}}\right) \times 100}{N_{T}}
$$

where $n_{\exp }$ is the amount of $\mathrm{H}_{2} \mathrm{O}$ adsorbed that has been measured experimentally at each pressure $(P)$ and temperature $(T), n_{\text {calc }}$ is the total amount of $\mathrm{H}_{2} \mathrm{O}$ adsorbed at the same pressure and temperature calculated by the model using eq 1 , $N_{\mathrm{A}}$ is the number of adsorption points measured at each temperature, and $N_{T}$ is the number of temperatures evaluated. Some physical constraints were imposed to the model parameters: it was assumed that only one molecule of water can be adsorbed on each oxygen surface group (the Langmuir saturation capacity, $n_{L}$, was forced to be equal or lower than the oxygen content of the carbon), and the value of $K_{1, T_{\text {ref }}}$ was forced to be greater than that of $K_{0, T_{\mathrm{rep}}}$ because water molecules present greater attraction to other water molecules than to the carbon surface. ${ }^{13}$ The values optimized following this criteria have been summarized in Table 1 .

Table 1. Optimal Parameters for the Extended CMMS Model for the Adsorption of $\mathrm{H}_{2} \mathrm{O}$ on the Evaluated Biochar

\begin{tabular}{ll} 
parameter & \multicolumn{1}{c}{ value } \\
$n_{\mathrm{L}}$ & $4.6252 \mathrm{mmol} \mathrm{g}^{-1}$ \\
$b_{\mathrm{L}, 30{ }^{\circ} \mathrm{C}}$ & $0.3518 \mathrm{kPa}^{-1}$ \\
$q_{\mathrm{L}}$ & $49336 \mathrm{~J} \mathrm{~mol}^{-1}$ \\
$n_{\text {sat }}$ & $4.6029 \mathrm{mmol} \mathrm{g}^{-1}$ \\
$K_{0,30^{\circ} \mathrm{C}}$ & $0.0055 \mathrm{kPa}^{-1}$ \\
$K_{1,30}{ }^{\circ} \mathrm{C}$ & $0.4912 \mathrm{kPa}^{-1}$ \\
$q_{0}$ & $37286 \mathrm{~J} \mathrm{~mol}^{-1}$ \\
$q_{1}$ & $44197 \mathrm{~J} \mathrm{~mol}^{-1}$ \\
MSE & 0.02
\end{tabular}

Dynamic Adsorption Experiments with Gas Mixtures. Dynamic experiments were carried out in the fixed-bed adsorption unit described in Part $1,{ }^{19}$ which is an improved version of that used in previous investigations. ${ }^{14-16}$ The bubbler humidifier has been replaced by a controlled evaporator mixer (CEM) coupled with a liquid delivery system (LDS) to feed liquid $\mathrm{H}_{2} \mathrm{O}$ (LIQUI-FLOW type, from Bronkhorst High Tech) and to two mass flow controllers (El-FLOW type, from Bronkhorst High Tech) that allow feeding a mixture of up to three components $\left(\mathrm{CO}_{2}, \mathrm{~N}_{2}\right.$, and $\left.\mathrm{H}_{2} \mathrm{O}_{(\mathrm{v})}\right)$ with the desired flow rate and composition. The original pressure transmitter of the adsorption unit, which had a working pressure range of $0-40$ bar, was substituted by a pressure transmitter of $0-2.5$ bar (Model A-10, WIKA) to gain accuracy in the low-pressure range $( \pm 0.5 \%$ of span), and the extra-column volume was reduced as described in Part $1 .{ }^{19}$ The mass flow rate of the stream leaving the adsorber is measured by a mini mass flow meter (CORI FLOW M13, from Bronkhorst High Tech) (measuring error: $\pm 0.5 \%$ of rate \pm zero stability). This device is sensitive to changes in ambient temperature (zero drift, $\pm 0.02 \mathrm{~g} \mathrm{~h}^{-1}{ }^{\circ} \mathrm{C}^{-1}$; span drift, $\pm 0.001 \%$ $\left.\mathrm{Rd}{ }^{\circ} \mathrm{C}^{-1}\right)$. To limit this effect, the zero offset is corrected just before starting each experiment, by leaving the device turned on and without flow for at least $30 \mathrm{~min}$ and then calibrating the zero of the instrument. However, for extended measuring periods, small absolute deviations of the mass flow rate can be observed related to changes in ambient temperature. Therefore, experimental data are not integrated over extended periods to avoid large cumulative errors. The temperature of the adsorbent is monitored by a thermocouple placed in the bulk of the bed at $4.7 \mathrm{~cm}$ from the feed end $\left( \pm 1^{\circ} \mathrm{C}\right)$. This can be kept constant by automatically actuating an electrical resistance coiled around the adsorption column or a compressed air valve. The effluent composition is analyzed by means of a humidity and temperature sensor (Hygroclip 2, from Rotronic) and by a dual channel gas microchromatograph (Model CP-4900, Varian).

In previous works carried out with different carbon adsorbents, the influence of $\mathrm{H}_{2} \mathrm{O}$ on $\mathrm{CO}_{2}$ adsorption was assessed by comparing the binary breakthrough curves obtained using dry mixtures of $\mathrm{CO}_{2}$ and $\mathrm{N}_{2}$ with ternary breakthrough curves obtained in the presence of $\mathrm{H}_{2} \mathrm{O}$ under similar conditions. $^{14,15}$ In this work, a similar approach has been followed, although the study has been taken further. To evaluate the effect of $\mathrm{CO}_{2}$ on $\mathrm{H}_{2} \mathrm{O}$ adsorption, the ternary $\mathrm{CO}_{2} / \mathrm{H}_{2} \mathrm{O} / \mathrm{N}_{2}$ breakthrough curve is also compared to the binary $\mathrm{H}_{2} \mathrm{O} / \mathrm{N}_{2}$ breakthrough curve obtained in the absence of $\mathrm{CO}_{2}$. Moreover, the worse scenario for $\mathrm{CO}_{2}$ adsorption has also been evaluated: a ternary $\mathrm{CO}_{2} / \mathrm{H}_{2} \mathrm{O} / \mathrm{N}_{2}$ breakthrough curve was obtained departing from a bed initially saturated with $\mathrm{H}_{2} \mathrm{O}$ and $\mathrm{N}_{2}$. Table 2 summarizes the experiments carried out. In all cases, the total pressure was $140 \mathrm{kPa}$, and the flow rate of the dry feed gas was the same used in Part $1:{ }^{19} 140 \mathrm{~cm}^{3} \mathrm{~min}^{-1}$ (volumetric flow rate given under standard pressure and temperature (STP) conditions $\left(0{ }^{\circ} \mathrm{C}\right.$ and $\left.\left.0.1 \mathrm{MPa}\right)\right)$, to which $0.14 \mathrm{~g} \mathrm{~h}^{-1}$ of water vapor were added by means of the LDSCEM system. Two sets of experiments were carried out: the first set (Cases 1-3) at ambient temperature, monitoring the adsorbent temperature but without actuating the temperature control, and at high relative humidity $(\mathrm{RH} \approx 95 \%)$, and the second set (Cases 4-7), under isothermal conditions $(\Delta T \leq$ $\pm 1{ }^{\circ} \mathrm{C}$ ), by automatically actuating the temperature control, 
Table 2. Experimental Conditions of the Dynamic Experiments Carried out in the Fixed-Bed Adsorption Unit, and Values of the Transport Parameters Used To Run the Simulations

\begin{tabular}{|c|c|c|c|c|c|c|c|c|c|}
\hline \multirow[b]{2}{*}{ Case } & \multicolumn{3}{|c|}{ Feed Composition (\%) } & \multirow[b]{2}{*}{$T\left({ }^{\circ} \mathrm{C}\right)$} & \multirow[b]{2}{*}{ gas in the adsorber at $t<0$} & \multirow{2}{*}{$\frac{\text { Mass-Transfer Coefficient, MTC }\left(\mathrm{s}^{-1}\right)}{\mathrm{H}_{2} \mathrm{O}}$} & \multicolumn{3}{|c|}{$\begin{array}{l}\text { Heat-Transfer Coefficients } \\
\qquad\left(\mathrm{W} \mathrm{m} \mathrm{m}^{-2} \mathrm{~K}^{-1}\right)\end{array}$} \\
\hline & $\mathrm{N}_{2}$ & $\mathrm{CO}_{2}$ & $\mathrm{H}_{2} \mathrm{O}$ & & & & $h_{\mathrm{w}}$ & HTC & $H_{\mathrm{amb}}$ \\
\hline 1 & 84 & 14 & 2 & $23^{b}$ & $100 \% \mathrm{~N}_{2}$ & 0.001 & 34 & 43 & 6 \\
\hline 2 & 98 & 0 & 2 & $23^{b}$ & $100 \% \mathrm{~N}_{2}$ & 0.001 & 37 & 46 & 6 \\
\hline 3 & 84 & 14 & 2 & $23^{b}$ & $2 \% \mathrm{H}_{2} \mathrm{O}+98 \% \mathrm{~N}_{2}$ & 0.001 & 34 & 43 & 6 \\
\hline 4 & 84 & 14 & 2 & 50 & $100 \% \mathrm{~N}_{2}$ & 0.06 & & & \\
\hline 5 & 98 & 0 & 2 & 50 & $100 \% \mathrm{~N}_{2}$ & 0.06 & & & \\
\hline 6 & 84 & 14 & 2 & 50 & $2 \% \mathrm{H}_{2} \mathrm{O}+98 \% \mathrm{~N}_{2}$ & 0.06 & & & \\
\hline 7 & 84 & 14 & 2 & 70 & $2 \% \mathrm{H}_{2} \mathrm{O}+98 \% \mathrm{~N}_{2}$ & 0.1 & & & \\
\hline
\end{tabular}

${ }^{a}$ Legend: $h_{\mathrm{w}}$, heat-transfer coefficient between the gas and the adsorber wall; HTC, heat-transfer coefficient between the gas and the adsorbent particles; and $H_{\mathrm{amb}}$, heat-transfer coefficient between the outer wall of the adsorber and the environment. ${ }^{b}$ The temperature of the adsorbent was not controlled during this experiment. The value shown corresponds to the average value of the ambient temperature during the experiment.

and at lower $\mathrm{RH}$. Cases $4-6$ were carried out at $50{ }^{\circ} \mathrm{C}(\mathrm{RH} \approx$ $22 \%)$, and Case 7 was performed at $70{ }^{\circ} \mathrm{C}(\mathrm{RH} \approx 9 \%)$.

Simulation of Dynamic Adsorption Experiments with Gas Mixtures. Breakthrough experiments were simulated using Aspen Adsorption V8.0, following the procedure detailed in Part $1 .{ }^{19}$ A summary of the model equations can be found in the Supporting Information. The IAS theory ${ }^{20}$ was used to model the multicomponent adsorption equilibrium based on the single-component adsorption models: the Toth model for the adsorption of $\mathrm{CO}_{2}$ and $\mathrm{N}_{2}$ and the extended CMMS model for the adsorption of $\mathrm{H}_{2} \mathrm{O}$. The results from the IAS-based simulations are compared with a simulation based directly on the pure component equilibrium models for comparison purposes. The energy balance was solved for Cases 1-3, making the following assumptions: the heat of adsorption of $\mathrm{H}_{2} \mathrm{O}$ was assumed to be constant and equal to the average isosteric heat of adsorption calculated from the slope of the isosteres, and the specific heat capacity of $\mathrm{H}_{2} \mathrm{O}$ in the adsorbed phase was taken to be the same as that of liquid water. Similarly, the heat of adsorption of $\mathrm{CO}_{2}$ and $\mathrm{N}_{2}$ were also assumed to be constant and equal to the values predicted by the Toth model, ${ }^{19}$ and the specific heat capacities of the adsorbed $\mathrm{CO}_{2}$ and $\mathrm{N}_{2}$ were assumed constant and approximated by the specific heat capacity of the gases calculated at the average temperature of the experiment, following the same criteria used in Part $1 .{ }^{19}$ The heat-transfer coefficient between the gas phase and the adsorbent (HTC) and the heat-transfer coefficient between the gas phase and the wall of the adsorber $\left(h_{\mathrm{w}}\right)$ were calculated for the feed conditions, using the correlations detailed in Part $1,{ }^{19}$ and were assumed to be constant during the experiments. The values of HTC and $h_{\mathrm{w}}$ used to run the simulations of Cases $1-3$ are shown in Table 2. The heattransfer coefficient between the outer wall of the adsorber and ambient air $\left(H_{\mathrm{amb}}\right)$ was assumed to be constant and equal to 6 $\mathrm{W} \mathrm{m}{ }^{-2} \mathrm{~K}^{-1}$. 9 The temperature of ambient air was assumed to be constant in the simulation, and set equal to the average value during the experiment. The simulation of Cases 4-7 was carried out assuming isothermal operation to mimic the experimental conditions. A lumped resistance model based on a linear driving force approximation in the solid phase was used to model the adsorption kinetics. This model presents the advantage that it requires less computational effort than the rigorous solution of the material balance at the particle level, and leads to similar results (see Part 1 for further details ${ }^{19}$ ). It has been previously reported that the adsorption of $\mathrm{H}_{2} \mathrm{O}$ on activated carbons follows a linear mass-transfer rate model, where the adsorption rate constant of $\mathrm{H}_{2} \mathrm{O}$ is dependent on the position of the isotherm. ${ }^{24,25}$ However, as a first approximation, the mass-transfer coefficients of the individual components $\left(\mathrm{MTC}_{i}\right)$ were assumed to be constant. The mass-transfer coefficients for $\mathrm{CO}_{2}$ were calculated from the effective diffusivities used to run the simulations in Part $1,{ }^{19}$ using the following relation:

$$
\mathrm{MTC}=\frac{15 D_{\mathrm{e}}}{R_{\mathrm{p}}{ }^{2}}
$$

where $D_{\mathrm{e}}$ is the effective diffusivity and $R_{\mathrm{p}}$ is the particle radius. In this work, only the mass-transfer coefficient of $\mathrm{H}_{2} \mathrm{O}$ has been adjusted to obtain a good fitting to the experimental results.

\section{RESULTS AND DISCUSSION}

Equilibrium of Adsorption of $\mathrm{H}_{2} \mathrm{O}_{(v)}$. The adsorption isotherms of $\mathrm{H}_{2} \mathrm{O}$ at 30,50 , and $70{ }^{\circ} \mathrm{C}$ up to the corresponding saturation pressure are shown in Figure 1. The maximum adsorption capacity is relatively low, compared to other adsorbents, such as zeolite $13 \mathrm{X},{ }^{26}$ or commercial activated carbons, such as BPL, ${ }^{27,28}$ which is beneficial from the point of view of its application, as a lower water holdup during $\mathrm{CO}_{2}$ capture operation can be expected by using the biochar evaluated here. Moreover, the shape of the $\mathrm{H}_{2} \mathrm{O}$ adsorption

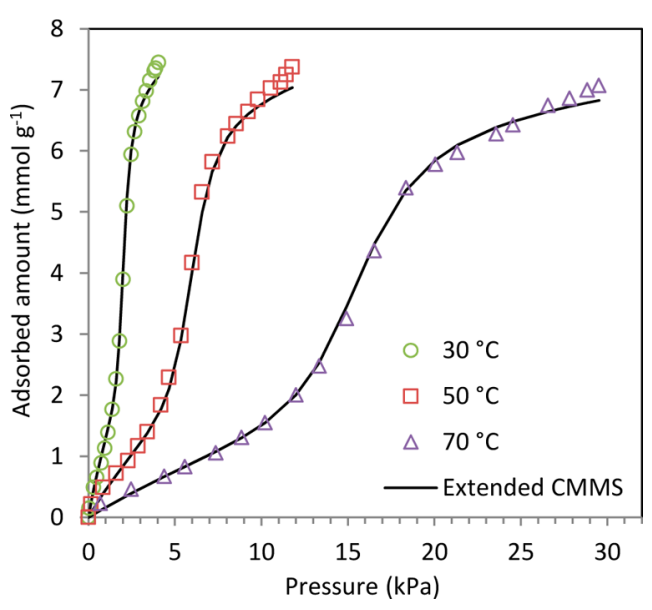

Figure 1. $\mathrm{H}_{2} \mathrm{O}$ adsorption isotherms at 30,50 , and $70{ }^{\circ} \mathrm{C}$ up to the corresponding saturation pressure; symbols represent experimental adsorption data and solid lines represent the extended CMMS adsorption model. 
isotherms (Type V) are also different from those of zeolite 13X, which are Type II. This means that the biochar presents even lower adsorption capacity at low relative pressures, while zeolite 13X presents high adsorption capacity from very low relative pressures. $^{29}$ This is also advantageous from the point of view of the economy of the process, as this facilitates the regeneration of the adsorbent either in a pressure swing process (a relatively small reduction of the pressure promotes a large drop in the $\mathrm{H}_{2} \mathrm{O}$ equilibrium capacity for the biochar) and also in a temperature swing process (a relatively small increase in temperature causes a large reduction in the relative humidity of the gas phase, which drastically reduces the $\mathrm{H}_{2} \mathrm{O}$ equilibrium adsorption capacity for the biochar).

Comparing the shape of the adsorption isotherms of $\mathrm{H}_{2} \mathrm{O}$ with those of $\mathrm{CO}_{2}$ and $\mathrm{N}_{2}$, ${ }^{19}$ it is clear that the adsorption of $\mathrm{H}_{2} \mathrm{O}$ follows a different mechanism. Detailed information about the mechanism of adsorption of water vapor on carbons can be found elsewhere. ${ }^{23,30}$ For the biochar under study, the hysteresis loop between the adsorption and desorption branches of $\mathrm{H}_{2} \mathrm{O}$ (not shown) is rather narrow, being almost negligible at the lowest temperature evaluated, which is related to its narrow pore size. ${ }^{16,21,31}$ Figure 1 shows that the extended CMMS model satisfactorily describes the $\mathrm{H}_{2} \mathrm{O}$ adsorption isotherms in the entire temperature and pressure range evaluated. In fact, the value of the mean squared error (MSE), shown in Table 1, is even lower than that of the Toth model for $\mathrm{CO}_{2}$ adsorption on the same adsorbent. ${ }^{19}$ The extended CMMS model presents the added advantage of providing a temperature-dependent equation for the adsorption of $\mathrm{H}_{2} \mathrm{O}$, which is very convenient for modeling purposes. The optimal parameters of the model are presented in Table 1 . The value of the affinity constant characterizes the attraction toward the oxygenated functional groups, although it is also affected by pore size and site density. Note that this is lower than $K_{1}$, because of the greater attraction between water molecules. As expected, the value of $q_{1}$ is greater than that of $q_{0}$, because water molecules present greater attraction to other water molecules than to the carbon surface. ${ }^{13}$ In fact, the value of $q_{1}$ matches that of the heat of condensation of water vapor. ${ }^{32}$ The value of $q_{\mathrm{L}}$, which represents the isosteric heat of adsorption at low loadings, is lower than that reported for carbon molecular sieve Takeda 5A, derived from coconut shell. ${ }^{10}$

Figure 2 represents the isosteric heat of adsorption of $\mathrm{H}_{2} \mathrm{O}$ versus the amount adsorbed compared to those of $\mathrm{CO}_{2}$ and $\mathrm{N}_{2}{ }^{19}$ As expected, the isosteric heat of adsorption of these adsorbates follows the trend $\mathrm{H}_{2} \mathrm{O}>\mathrm{CO}_{2}>\mathrm{N}_{2}$. The isosteric heat of adsorption of $\mathrm{H}_{2} \mathrm{O}$ decreases slightly at low loadings and increases also slightly at high loadings, being almost constant at intermediate loadings, with an average value of 45 $\mathrm{kJ} \mathrm{mol}^{-1}$, which is close to the heat of vaporization of water (43 $\mathrm{kJ} \mathrm{mol}{ }^{-1}$ at $50{ }^{\circ} \mathrm{C}^{32}$ ). This value is similar to those observed for other biomass-based microporous carbons (44-46 kJ $\left.\mathrm{mol}^{-1}\right),{ }^{14,15}$ and significantly lower than that of zeolite $13 \mathrm{X}$ (54-62 kJ mol ${ }^{-1}$ for loadings of 3-12 $\left.\mathrm{mol} \mathrm{kg}^{-1}\right){ }^{33}$

Nonisothermal Dynamic Adsorption Experiments with Gas Mixtures at High Relative Humidity (RH). Figure 3 presents the results of Case 1: a ternary breakthrough curve carried out with $84 \% \mathrm{~N}_{2}, 14 \% \mathrm{CO}_{2}$, and $2 \% \mathrm{H}_{2} \mathrm{O}$ over a fresh adsorbent bed at room temperature (see Table 2 for further details). The $\mathrm{CO}_{2}$ adsorption front travels through the bed much faster than $\mathrm{H}_{2} \mathrm{O}$ : the breakthrough time of $\mathrm{CO}_{2}$ is 4-5 min (see Figure 3c), while that of $\mathrm{H}_{2} \mathrm{O}$ is $127 \mathrm{~min}$ (see Figure $3 \mathrm{~b}$ ). This is due to two main reasons: the molar flow rate

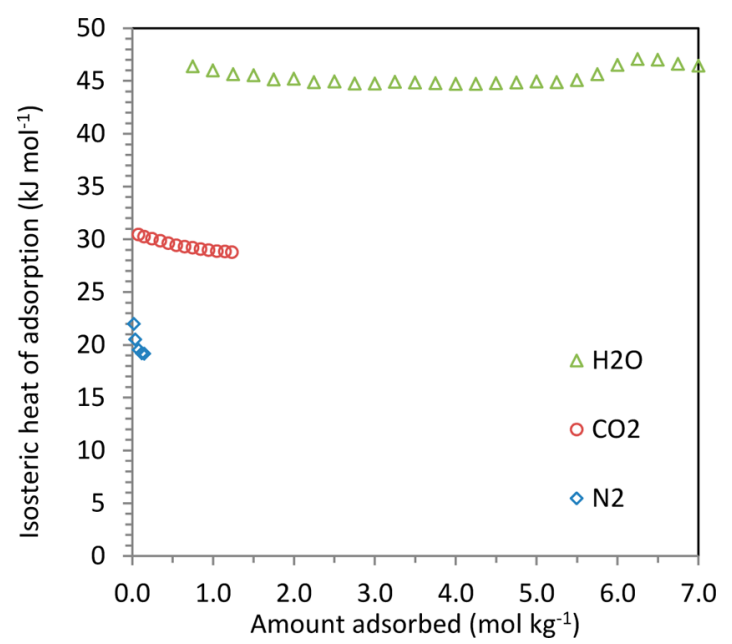

Figure 2. Isosteric heat of adsorption of $\mathrm{H}_{2} \mathrm{O}, \mathrm{CO}_{2}$, and $\mathrm{N}_{2}$ on the evaluated biochar.

of $\mathrm{CO}_{2}$ fed to the adsorber is $\sim 7$ times greater than that of $\mathrm{H}_{2} \mathrm{O}$, and the equilibrium adsorption capacity for pure $\mathrm{H}_{2} \mathrm{O}$ at the relative humidity of the feed $(\mathrm{RH} \approx 95 \%)$ is $>11$ times greater than that of the pure adsorption capacity of $\mathrm{CO}_{2}$ at the partial pressure of $\mathrm{CO}_{2}$ in the feed. It is important to highlight that the breakthrough time of $\mathrm{CO}_{2}$ is not affected by the presence of $\mathrm{H}_{2} \mathrm{O}$ in the feed: it is similar to that obtained for the same adsorbent under dry conditions, ${ }^{19}$ which is in good agreement with previous experimental studies carried out by our group using different carbon adsorbents. ${ }^{14-16}$ Breakthrough capacity for $\mathrm{CO}_{2}$ is not affected by $\mathrm{H}_{2} \mathrm{O}$, because the adsorption front of $\mathrm{H}_{2} \mathrm{O}$ is delayed, compared to that of $\mathrm{CO}_{2}$ (the gas phase between the adsorption front of $\mathrm{H}_{2} \mathrm{O}$ and that of $\mathrm{CO}_{2}$ is a dry mixture of $\mathrm{CO}_{2}$ and $\mathrm{N}_{2}$ ). However, a small roll-up phenomenon can be observed in the detail of the $\mathrm{CO}_{2}$ curve shown in Figure 3d: as the front of $\mathrm{H}_{2} \mathrm{O}$ travels through the bed, part of the $\mathrm{CO}_{2}$ initially adsorbed is displaced by the adsorption of $\mathrm{H}_{2} \mathrm{O}$. As can be seen from Figures $3 \mathrm{c}$ and $3 \mathrm{~d}$, the IAS-based simulation (dashed lines) reproduces the experimental breakthrough curve of $\mathrm{CO}_{2}$ (symbols) better than the simulation that is based solely on the pure component equilibrium models (solid lines), which is in good agreement with the behavior observed under dry conditions. ${ }^{19}$ Only the IAS-based simulation can reproduce the roll-up observed in the $\mathrm{CO}_{2}$ curve due to the coadsorption of $\mathrm{H}_{2} \mathrm{O}$.

The breakthrough curve of $\mathrm{H}_{2} \mathrm{O}$, shown in Figure 3b, presents two uptake zones with an intermediate plateau, as expected for the equilibrium of adsorption of $\mathrm{H}_{2} \mathrm{O}$ (Figure 1) and the high relative humidity of the feed, in good agreement with the results obtained for other carbon adsorbents. ${ }^{14-16}$ The intermediate plateau corresponds to the inflection point of the adsorption isotherm, which occurs at $\mathrm{RH} \approx 40 \%$. This behavior is obviously reflected in the evolution of the molar fraction of $\mathrm{CO}_{2}$ and $\mathrm{N}_{2}$. As can be seen from Figure $3 \mathrm{~b}$, the breakthrough curve of $\mathrm{H}_{2} \mathrm{O}$ is only approximately described by the IAS-based simulation, and the simulation based on the equilibrium of adsorption of the pure components reproduces better the shape of the experimental curve, although it is shifted to its right. This can be partly attributed to the progressive cooling of ambient air during Case 1 , from $24{ }^{\circ} \mathrm{C}$ at $t=0$, to $22{ }^{\circ} \mathrm{C}$ at $t=900 \mathrm{~min}$, which was not considered in the simulations, which considered that, at $t=0$, the adsorbent was in equilibrium with pure nitrogen at $24^{\circ} \mathrm{C}$, but during the experiment, the ambient and 

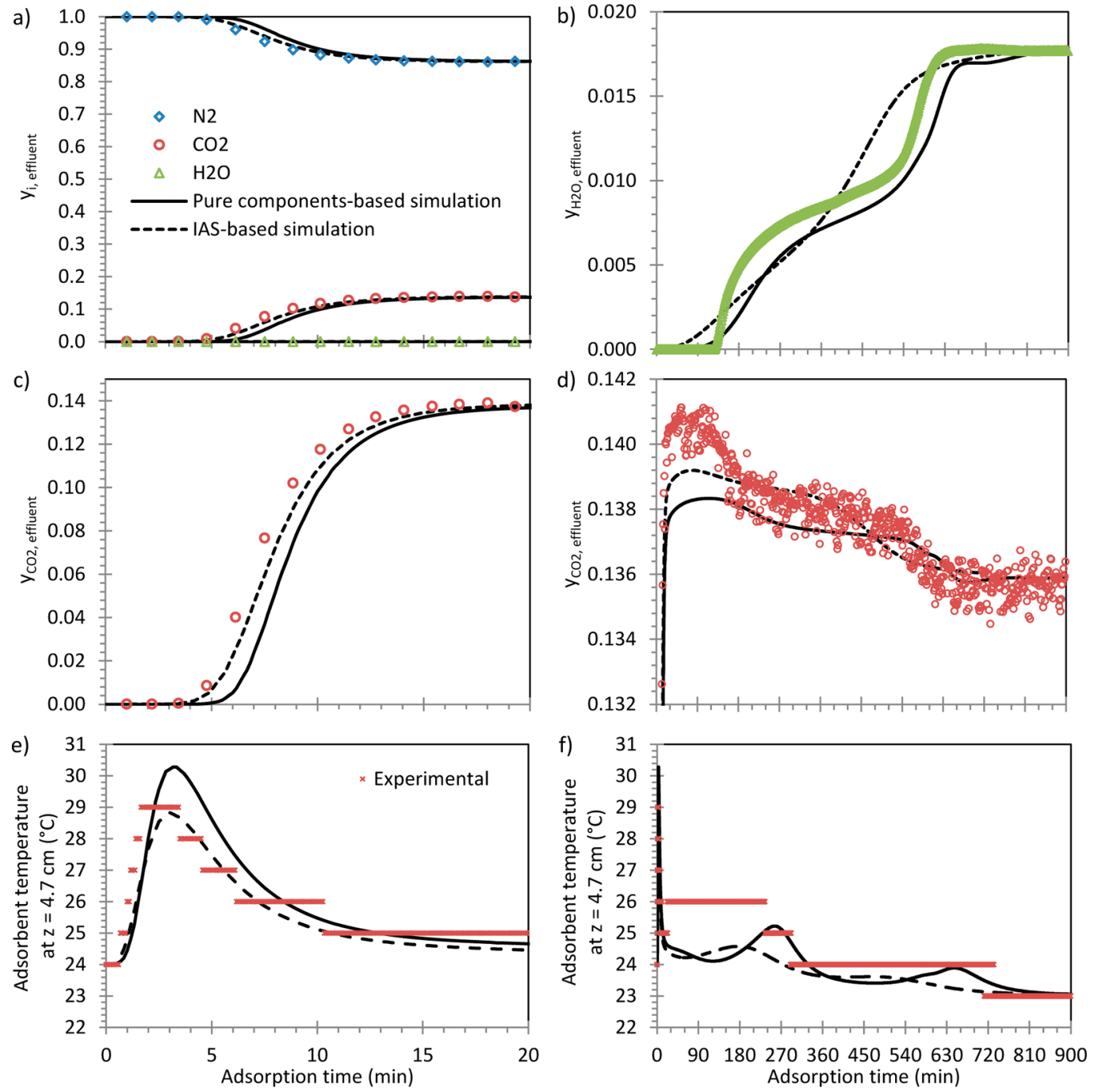

Figure 3. Case 1: breakthrough curve of a ternary mixture with $84 \% \mathrm{~N}_{2}, 14 \% \mathrm{CO}_{2}$, and $2 \% \mathrm{H}_{2} \mathrm{O}$ at $140 \mathrm{kPa}$ and room temperature over the adsorbent bed in equilibrium with $\mathrm{N}_{2}$ at $t=0$; (a) evolution of the molar fraction of $\mathrm{N}_{2}, \mathrm{CO}_{2}$ and $\mathrm{H}_{2} \mathrm{O}$ in the effluent during the first 20 min of the experiment; (b) full breakthrough curve of $\mathrm{H}_{2} \mathrm{O}$; (c) breakthrough curve of $\mathrm{CO}_{2}$; (d) roll-up detail of the $\mathrm{CO}_{2}$ breakthrough curve; (e, f) temperature history of the adsorbent at $4.7 \mathrm{~cm}$ from the feed end. The symbols represent the experimental data, the solid lines represent the results obtained by simulation using the pure component adsorption models, and the dashed lines represent the results obtained by simulation making use of IAS theory.

feed temperature were constant and equal to the average temperature of ambient air during Case 1: $23{ }^{\circ} \mathrm{C}$. Note that only the MTC value of $\mathrm{H}_{2} \mathrm{O}$ was fitted to reproduce the experimental results. The fitted value $\left(0.001 \mathrm{~s}^{-1}\right)$ is in good agreement with the linear adsorption rate constants reported for $\mathrm{H}_{2} \mathrm{O}$ adsorption on a microporous coconut shell activated carbon at $24{ }^{\circ} \mathrm{C}\left(0.0005-0.003 \mathrm{~s}^{-1}\right){ }^{24}$ This corresponds to an effective diffusivity of $8 \times 10^{-11} \mathrm{~m}^{2} \mathrm{~s}^{-1}$, which is in good agreement with the self-diffusion coefficient of $\mathrm{H}_{2} \mathrm{O}$ reported for microporous activated carbons with pore widths in the range of $0.4-1.5 \mathrm{~nm}$ at $25^{\circ} \mathrm{C}: 2 \times 10^{-11}-5 \times 10^{-10} \mathrm{~m}^{2} \mathrm{~s}^{-1} .34$ The effective diffusivity of $\mathrm{H}_{2} \mathrm{O}$ is expected to be smaller than that of $\mathrm{CO}_{2}$, because of the higher isosteric heat of $\mathrm{H}_{2} \mathrm{O}$ adsorption. $^{35}$

The experimental temperature history of the adsorbent during Case 1 is shown in Figure 3f. It presents two distinct thermal waves. The first, enlarged in Figure $3 \mathrm{e}$, reaches its maximum within $\sim 2 \mathrm{~min}$ and is due to the adsorption of $\mathrm{CO}_{2}$. This presents the largest shift in temperature $\left(\Delta T_{\max }=5{ }^{\circ} \mathrm{C}\right)$, despite the lower heat of adsorption of $\mathrm{CO}_{2}$, compared to that of $\mathrm{H}_{2} \mathrm{O}$, because the adsorption of $\mathrm{CO}_{2}$ takes places in a shorter time $(\sim 15 \mathrm{~min})$, compared to that of $\mathrm{H}_{2} \mathrm{O}(\sim 720 \mathrm{~min})$, and thus the heat released due to adsorption has less time to dissipate (the adsorber is not isolated from ambient air). On the other hand, the adsorption of $\mathrm{H}_{2} \mathrm{O}$ causes a wider but shorter thermal wave $\left(\Delta T_{\max }=2{ }^{\circ} \mathrm{C}\right)$, which is shown in Figure 3f. Note that this temperature effect is almost negligible, compared to the thermal wave of $100{ }^{\circ} \mathrm{C}$ reported for zeolite $13 \mathrm{X}^{8}$ This is an important advantage from the operation point of view, as the temperature rise associated with adsorption reduces the working capacity of the adsorbent during cyclic operation. As can be seen from Figures $3 \mathrm{e}$ and $3 \mathrm{f}$, the simulation results for the adsorbent temperature are in good agreement with the experimental results, which validates the assumptions made to solve the energy balance, in good agreement with the results of Part $1 .{ }^{19}$ The temperature rise predicted by the pure component models is slightly above that based on IAS, because of the lower adsorption capacity predicted by IAS for competitive adsorption. 

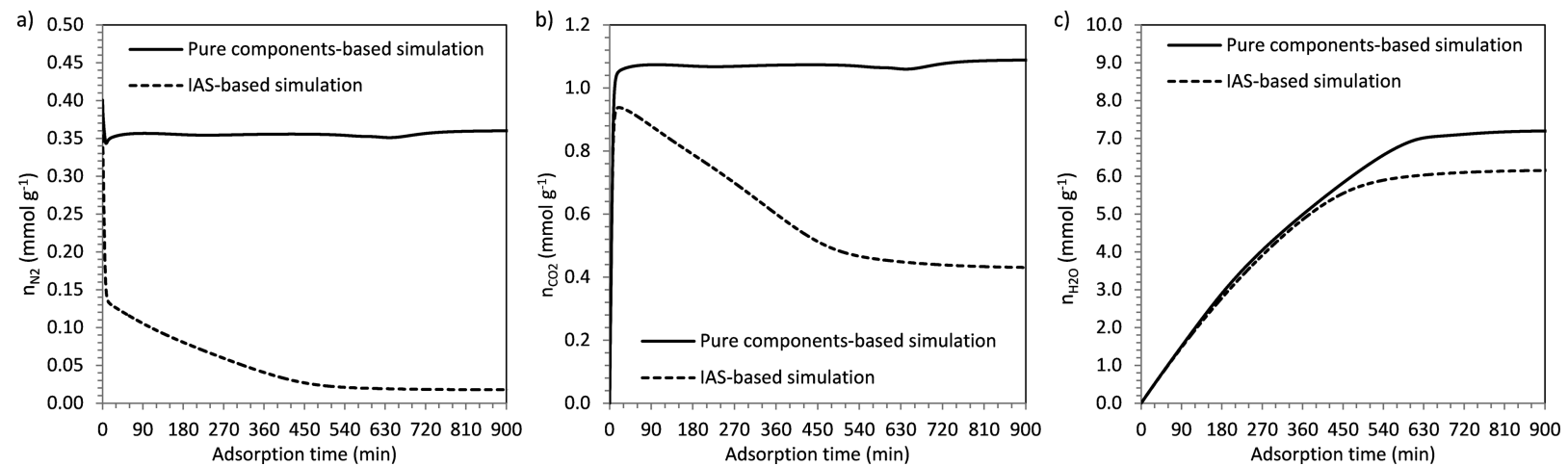

Figure 4. Cumulative adsorbed amount versus time for Case 1: (a) $\mathrm{N}_{2}$, (b) $\mathrm{CO}_{2}$, and (c) $\mathrm{H}_{2} \mathrm{O}$.

To better understand what is happening, the cumulative amount of $\mathrm{N}_{2}, \mathrm{CO}_{2}$, and $\mathrm{H}_{2} \mathrm{O}$ adsorbed during Case 1 were plotted versus time in Figure 4. Only the simulation results are shown, because the cumulative error associated with the integration of the experimental data due to small absolute differences in the inlet and outlet flow rate increases with the integration time. Figure $4 \mathrm{a}$ shows the plot for $\mathrm{N}_{2}$ : the simulation based on the equilibrium of adsorption of the pure components shows a fast and small reduction in the loading of $\mathrm{N}_{2}$, which is solely due to the decrease of the partial pressure of $\mathrm{N}_{2}$ in the gas phase at the beginning of the experiment; the $\mathrm{N}_{2}$ loading holds almost constant during the rest of the experiment, as the competition with $\mathrm{CO}_{2}$ and $\mathrm{H}_{2} \mathrm{O}$ for the adsorption sites is not considered. On the other hand, the IAS-based simulation predicts a greater decrease in the $\mathrm{N}_{2}$ loading, which occurs in two stages: the first, which is faster $(\sim 10 \mathrm{~min})$, is due to the adsorption of $\mathrm{CO}_{2}$, and the second, which is much slower, is due to the adsorption of $\mathrm{H}_{2} \mathrm{O}$. At equilibrium, IAS predicts a reduction of $95 \%$ in the adsorption capacity of $\mathrm{N}_{2}$, compared to the pure component adsorption model, under the experimental conditions evaluated. Figure $4 \mathrm{~b}$ shows the plot for the cumulative adsorbed amount of $\mathrm{CO}_{2}$ versus time for Case 1: the simulation based solely on the equilibrium of adsorption of the pure components shows a rapid increase in $\mathrm{CO}_{2}$ loading, which is due to the step change in the feed composition, and this holds almost constant during the rest of the experiment, because the competition with $\mathrm{H}_{2} \mathrm{O}$ for the adsorption sites is not considered. The IAS-based simulation also predicts a rapid increase of the $\mathrm{CO}_{2}$ loading, but this goes through a maximum at $20 \mathrm{~min}$, and then decreases due to the displacement of part of the adsorbed $\mathrm{CO}_{2}$ by the adsorption of $\mathrm{H}_{2} \mathrm{O}$, until it stabilizes at a lower value (once the adsorbent reaches equilibrium with the feed gas). Up to $5 \mathrm{~min}$, both simulations give coincident results that are in good agreement with the experimental data. This is of utmost importance, as the step times involved in swing adsorption cycles are on the order of seconds or just a few minutes. However, at equilibrium, IAS predicts a reduction in the $\mathrm{CO}_{2}$ adsorption capacity of $60 \%$, compared to the pure component adsorption model. Although the reduction is significant, this is still lower than the $99 \%$ reduction reported for zeolite $13 \mathrm{X}$ for similar $\mathrm{RH}$ values. ${ }^{8}$ Figure $4 \mathrm{c}$ shows a plot of the cumulative amount of $\mathrm{H}_{2} \mathrm{O}$ adsorbed versus time for Case 1: this increases monotonically up to the saturation capacity for the two simulation runs carried out, although, for the IAS-based simulation, this is $15 \%$ lower than that of the simulation based on the pure component adsorption models.
In Case 1, the adsorbent bed was initially regenerated (free of $\mathrm{CO}_{2}$ and $\mathrm{H}_{2} \mathrm{O}$ ). This is the best scenario, in terms of breakthrough capacity, but it is unlikely to be the case during cyclic operation, where regeneration is expected to be interrupted before completion. To further assess the influence that water holdup can represent to $\mathrm{CO}_{2}$ adsorption in real cyclic operation, the worst scenario was evaluated: the adsorbent bed was first saturated with a gas feed with high relative humidity $(\mathrm{RH}=95 \%)$, by running a breakthrough curve with a binary mixture with $98 \% \mathrm{~N}_{2}$ and $2 \% \mathrm{H}_{2} \mathrm{O}$ at room temperature (Case 2), and subsequently, a ternary mixture containing $84 \% \mathrm{~N}_{2}, 14 \% \mathrm{CO}_{2}$, and $2 \% \mathrm{H}_{2} \mathrm{O}$ was fed to the adsorbent initially saturated with $\mathrm{H}_{2} \mathrm{O}$ (Case 3).

The results of Case 2 are shown in Figure 5. The shape of the breakthrough curve of $\mathrm{H}_{2} \mathrm{O}$, shown in Figure 5a, is similar to that of Case 1, although the experimental breakthrough time of $\mathrm{H}_{2} \mathrm{O}$ is higher than that observed in Case 1; this is attributed to the lower temperature of the adsorbent at $t=0$ for Case 2: 22 ${ }^{\circ} \mathrm{C}$, versus $24{ }^{\circ} \mathrm{C}$ in Case 1 . As can be seen from Figure 5a, both simulations provide a satisfactory description of the full breakthrough curve of $\mathrm{H}_{2} \mathrm{O}$. The difference between the simulation based on the pure component adsorption models and that based on IAS theory is small, because of the low adsorption capacity of the carbon toward $\mathrm{N}_{2}$. The plots of the cumulative amount of $\mathrm{N}_{2}$ and $\mathrm{H}_{2} \mathrm{O}$ adsorbed versus time for the two simulation runs can be found in the Supporting Information. Even though the $\mathrm{H}_{2} \mathrm{O}$ loading is similar for both simulations, the effect of competitive adsorption on the loading of $\mathrm{N}_{2}$ (weak adsorbate) is significant: at equilibrium, the IASbased simulation predicts a drop in the $\mathrm{H}_{2} \mathrm{O}$ loading of only $2 \%$, compared to the pure component adsorption model, but 93\% for $\mathrm{N}_{2}$. The experimental temperature history of the adsorbent, shown in Figure 5b, shows a wide thermal wave that is adequately reproduced by the simulation results. A sensitivity analysis was carried out to evaluate the influence of the masstransfer coefficient of $\mathrm{H}_{2} \mathrm{O}$ on the results of the IAS-based simulation (results can be found in the Supporting Information). If the mass-transfer coefficient of $\mathrm{H}_{2} \mathrm{O}$ is increased from $0.001 \mathrm{~s}^{-1}$ to $0.002 \mathrm{~s}^{-1}$, a better fit of the experimental curve on the initial and final stages is obtained, although no difference is observed in the intermediate region. Nevertheless, the experimental curve still presents a sharper breakthrough than the simulated curve. The breakthrough time of the simulation is not substantially modified if the MTC is increased above $0.002 \mathrm{~s}^{-1}$.

The results of Case 3 are presented in Figure 6. The breakthrough time of $\mathrm{CO}_{2}$, shown in Figure 6a, is reduced compared to Case 1 , because of the high amount of $\mathrm{H}_{2} \mathrm{O}$ 

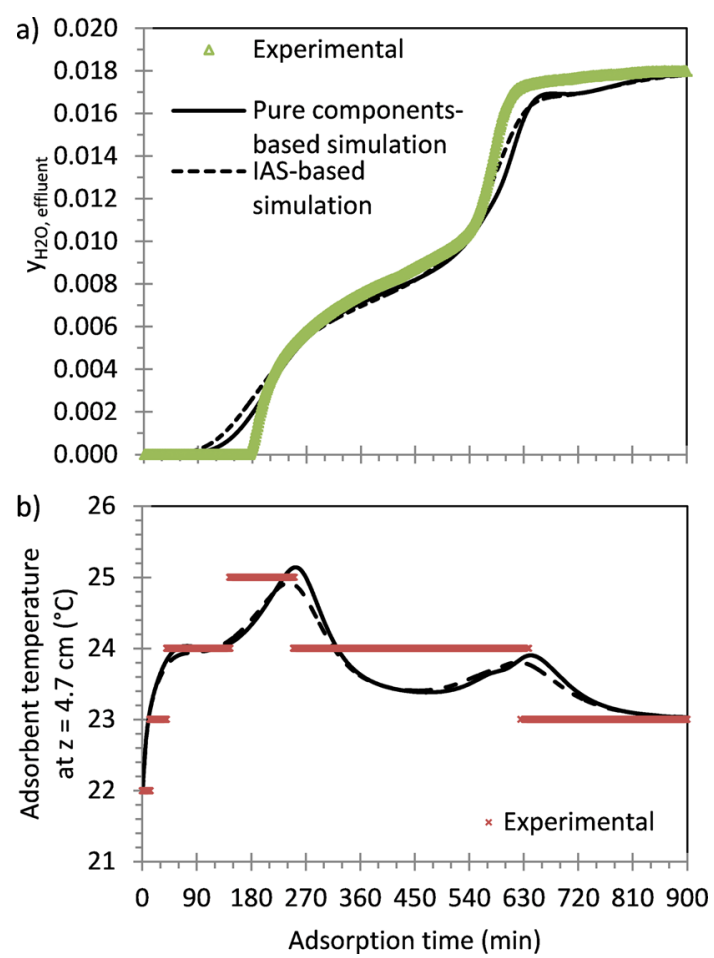

Figure 5. Case 2: breakthrough curve of a binary mixture with $98 \% \mathrm{~N}_{2}$ and $2 \% \mathrm{H}_{2} \mathrm{O}$ at $140 \mathrm{kPa}$ and room temperature over the adsorbent bed in equilibrium with $\mathrm{N}_{2}$ at $t=0$ : (a) molar fraction of $\mathrm{H}_{2} \mathrm{O}$ in the effluent; (b) temperature history of the bed at $4.7 \mathrm{~cm}$ from the feed end. The symbols represent the experimental data, the solid lines represent the results obtained by simulation using the pure component adsorption models, and the dashed lines represent the results obtained by simulation making use of the IAS theory.

initially adsorbed on the biochar. Note that Case 3 constitutes the worst-case scenario: an adsorbent initially in equilibrium with a feed almost saturated with $\mathrm{H}_{2} \mathrm{O}$ (the relative humidity of the feed gas at $t=0$ was $95 \%$ ). Under cyclic operation, and even for a high inlet $\mathrm{RH}$ value, the $\mathrm{H}_{2} \mathrm{O}$ loading can be kept low by an appropriate cycle design (selection of adsorption step times, regeneration conditions, etc.). Figure $6 \mathrm{~b}$ shows the shift observed in the adsorbent temperature due to $\mathrm{CO}_{2}$ adsorption: $\Delta T_{\max }=2{ }^{\circ} \mathrm{C}$. This is half of that observed in Case 1 , because of the lower amount of $\mathrm{CO}_{2}$ adsorbed in Case 3. As can be seen from Figure 6, the simulation carried out using the IAS theory satisfactorily reproduces the breakthrough curve of $\mathrm{CO}_{2}$ and the thermal wave observed experimentally. However, the IASbased simulation predicts a rollup in the partial pressure of $\mathrm{H}_{2} \mathrm{O}$ that is due to the adsorption of $\mathrm{CO}_{2}$, which is not observed experimentally (see Figure 6a). The pure component-based simulation shows a small bump in the partial pressure of $\mathrm{H}_{2} \mathrm{O}$ simultaneous with the breakthrough of $\mathrm{CO}_{2}$ (see Figure 6a). Note that this is only related to the desorption of $\mathrm{H}_{2} \mathrm{O}$ that would be expected due to the larger temperature rise that would occur for pure $\mathrm{CO}_{2}$ adsorption, and not to displacement by $\mathrm{CO}_{2}$ adsorption (if the simulation is carried out using the pure component equilibrium models but assuming isothermal operation, the bump in the $\mathrm{H}_{2} \mathrm{O}$ curve disappears). The cumulative adsorbed amount versus time for Case 3 can be seen in the Supporting Information. At equilibrium, IAS theory predicts a reduction of $96 \%$ in the loading of $\mathrm{N}_{2}$, compared to the pure component adsorption model due to competition with $\mathrm{CO}_{2}$ and $\mathrm{H}_{2} \mathrm{O}$. The loading of $\mathrm{CO}_{2}$ estimated by the IAS-based
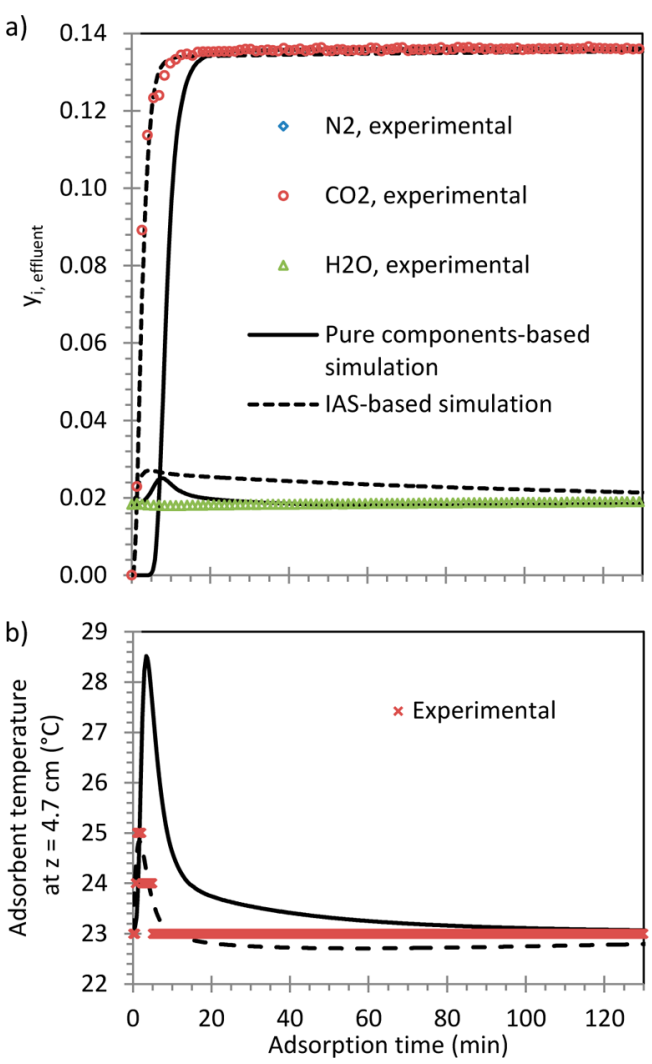

Figure 6. Case 3: breakthrough curve of a ternary mixture with $84 \%$ $\mathrm{N}_{2}, 14 \% \mathrm{CO}_{2}$, and $2 \% \mathrm{H}_{2} \mathrm{O}$ at $140 \mathrm{kPa}$ and room temperature over the adsorbent in equilibrium with $98 \% \mathrm{~N}_{2}$ and $2 \% \mathrm{H}_{2} \mathrm{O}$ at $t=0$ : (a) evolution of the molar fraction of $\mathrm{CO}_{2}$ and $\mathrm{H}_{2} \mathrm{O}$ in the effluent; (b) temperature history of the bed at $4.7 \mathrm{~cm}$ from the feed end. The symbols represent the experimental data, the solid lines represent the results obtained by simulation using the pure component adsorption models, and the dashed lines represent the results obtained by simulation making use of the IAS theory.

simulation is similar to that of the pure component up to $1 \mathrm{~min}$ of adsorption but then tends toward a value that is $64 \%$ lower than that expected for the pure component equilibrium model. The amount of $\mathrm{H}_{2} \mathrm{O}$ adsorbed calculated by the simulation based on the equilibrium of adsorption of the pure components remains almost constant, as the competition with $\mathrm{CO}_{2}$ is not considered. On the other hand, the IAS-based simulation predicts a gradual decrease in the loading of $\mathrm{H}_{2} \mathrm{O}$ due to the adsorption of $\mathrm{CO}_{2}$ that has not been observed experimentally.

Isothermal Dynamic Adsorption Experiments with Gas Mixtures at Low Relative Humidity (RH). Cases 1-3 were carried out at room temperature (without temperature control) for two main reasons: to obtain experimental data for the temperature in order to validate the nonisothermal model, and also to test the behavior of the adsorbent under high relative humidity (worst-case scenario). However, the temperature of flue gas in postcombustion applications will be likely above $23{ }^{\circ} \mathrm{C}$ to avoid cooling. For this reason, additional breakthrough experiments (Cases 4-7) were carried out at 50 and $70{ }^{\circ} \mathrm{C}$ to check the validity of the model at higher temperatures. To guarantee that no condensation would occur in the extra column volume of the unit (which is at room temperature), the absolute amount of $\mathrm{H}_{2} \mathrm{O}$ in the feed of Cases 4-7 was kept equal to that of Cases 1-3, which means that the $\mathrm{RH}$ value of Cases 4-7 is lower than that of Cases 1-3. 
Therefore, the results will also be useful to evaluate the effect of the $\mathrm{RH}$ value of the feed gas.

Figure 7 shows the experimental and simulation results of Case 4: a ternary breakthrough curve for a gas feed consisting

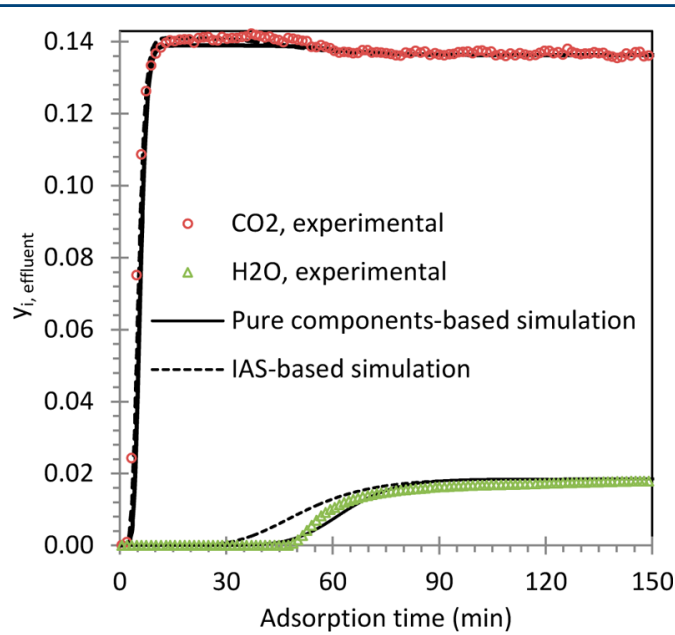

Figure 7. Case 4: breakthrough curve of a ternary mixture with $84 \%$ $\mathrm{N}_{2}, 14 \% \mathrm{CO}_{2}$, and $2 \% \mathrm{H}_{2} \mathrm{O}$ at $140 \mathrm{kPa}$ and $50{ }^{\circ} \mathrm{C}$, over the adsorbent in equilibrium with $\mathrm{N}_{2}$ at $t=0$. The symbols represent the experimental data, the solid lines represent the results obtained by simulation using the pure component adsorption models, and the dashed lines represent the results obtained by simulation making use of the IAS theory.

of $84 \% \mathrm{~N}_{2}, 14 \% \mathrm{CO}_{2}$, and $2 \% \mathrm{H}_{2} \mathrm{O}$ at $50{ }^{\circ} \mathrm{C}$, departing from a fully regenerated adsorbent bed. As expected, the breakthrough time of $\mathrm{CO}_{2}$ is lower than that of Case 1 , because of the higher temperature of the adsorber in Case 4. The IAS-based simulation provides a satisfactory description of the experimental breakthrough curve of $\mathrm{CO}_{2}$, including the roll-up phenomenon that occurs due to the displacement of part of the initially adsorbed $\mathrm{CO}_{2}$ by the preferential adsorption of $\mathrm{H}_{2} \mathrm{O}$. On the other hand, the experimental breakthrough curve of $\mathrm{H}_{2} \mathrm{O}$ is better described by the simulation results based on the pure component equilibrium models. The experimental breakthrough curve of $\mathrm{H}_{2} \mathrm{O}$ shows a single uptake zone which differs from the two uptake zones observed in Case 1 . Although the total feed flow rate and its content in $\mathrm{H}_{2} \mathrm{O}$ is the same for both experiments, in Case 4, the temperature of the adsorbent was kept constant at $50{ }^{\circ} \mathrm{C}$, which means that the relative humidity of the inlet gas was $\sim 21 \%$. On the other hand, Case 1 was carried out at room temperature $\left(\sim 23^{\circ} \mathrm{C}\right)$, and the relative humidity of the inlet gas was ca. $95 \%$. A RH value of $21 \%$ corresponds to the first term of eq 1 (the Langmuir model), so the breakthrough curve is that expected for favorable equilibrium. ${ }^{17}$ The MTC of $\mathrm{H}_{2} \mathrm{O}$ used to run the simulations shown in Figure 7 was $0.06 \mathrm{~s}^{-1}$. A sensitivity analysis was carried out to evaluate the influence of the MTC of $\mathrm{H}_{2} \mathrm{O}$ on the simulation results: increasing the MTC of $\mathrm{H}_{2} \mathrm{O}$ above $0.06 \mathrm{~s}^{-1}$ had no significant effect on the simulated curves; however, if the MTC of $\mathrm{H}_{2} \mathrm{O}$ is decreased to $0.05 \mathrm{~s}^{-1}$, the mass transfer of $\mathrm{H}_{2} \mathrm{O}$ becomes rate-limiting for the IAS-based simulation, giving a poorer fit to the experimental $\mathrm{CO}_{2}$ rollup.

The plots of the cumulative adsorbed amounts of $\mathrm{N}_{2}, \mathrm{CO}_{2}$, and $\mathrm{H}_{2} \mathrm{O}$ versus time for the two simulation runs carried out for Case 4 can be found in the Supporting Information. The trends are similar to those observed for Case 1. Nevertheless, the reduction in the equilibrium capacity predicted by IAS compared to the pure component adsorption models is significantly lower than that of Case 1 for $\mathrm{N}_{2}$ and $\mathrm{CO}_{2}: 54 \%$ and $23 \%$, respectively, because of the lower relative humidity of the feed gas $(\mathrm{RH} \approx 21 \%)$.

The results for Case 5, a binary breakthrough curve for a gas feed consisting of $2 \% \mathrm{H}_{2} \mathrm{O}$ (balance $\mathrm{N}_{2}$ ) at $50{ }^{\circ} \mathrm{C}$ departing from a fully regenerated adsorbent bed, can be found in the Supporting Information. As in Case 4, which was carried out at the same temperature and for the same $\mathrm{H}_{2} \mathrm{O}$ content in the feed, the breakthrough curve of $\mathrm{H}_{2} \mathrm{O}$ shows a single uptake zone. The experimental breakthrough time of $\mathrm{H}_{2} \mathrm{O}$ of Cases 4 and 5 is very close ( $49 \mathrm{~min}$ vs $48 \mathrm{~min}$ ), which means that $\mathrm{H}_{2} \mathrm{O}$ is not significantly affected by $\mathrm{CO}_{2}$ adsorption (similar results were also obtained at $70{ }^{\circ} \mathrm{C}$ ). The results from the pure component adsorption models-based simulation and the IASbased simulation are close due to the low adsorption capacity toward $\mathrm{N}_{2}$, compared to that of $\mathrm{H}_{2} \mathrm{O}$, as discussed for Case 2 . IAS predicts a reduction in the equilibrium adsorption capacity of $6 \%$ for $\mathrm{H}_{2} \mathrm{O}$ and $37 \%$ for $\mathrm{N}_{2}$, compared to the singlecomponent adsorption models. Note that the smaller reduction in the $\mathrm{N}_{2}$ adsorption capacity, compared to Case 2 , is due to the lower adsorption capacity of $\mathrm{H}_{2} \mathrm{O}$ at the lower relative humidity of the gas phase $(\mathrm{RH} \approx 22 \%)$.

Figure 8 represents the results for Case 6: a ternary breakthrough curve for a gas feed consisting of $84 \% \mathrm{~N}_{2}, 14 \%$

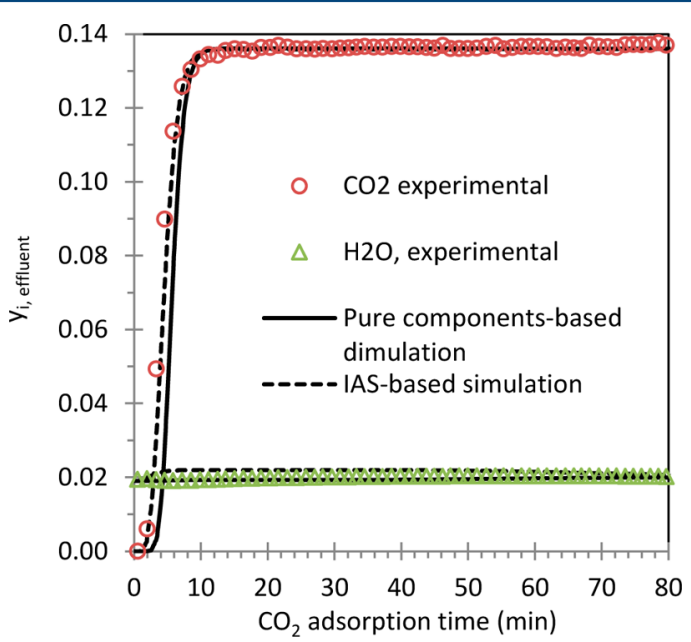

Figure 8. Case 6: breakthrough curve of a ternary mixture with $84 \%$ $\mathrm{N}_{2}, 14 \% \mathrm{CO}_{2}$, and $2 \% \mathrm{H}_{2} \mathrm{O}$ at $140 \mathrm{kPa}$ and $50{ }^{\circ} \mathrm{C}$, over the adsorbent in equilibrium with $98 \% \mathrm{~N}_{2}$ and $2 \% \mathrm{H}_{2} \mathrm{O}$ at $t=0$. The symbols represent the experimental data, the solid lines represent the results obtained by simulation using the pure component adsorption models, and the dashed lines represent the results obtained by simulation making use of the IAS theory.

$\mathrm{CO}_{2}$, and $2 \% \mathrm{H}_{2} \mathrm{O}$ at $50{ }^{\circ} \mathrm{C}$ departing from a fully saturated adsorbent bed with $2 \% \mathrm{H}_{2} \mathrm{O}$ and $98 \% \mathrm{~N}_{2}$ at $50{ }^{\circ} \mathrm{C}$ (Case 6 was carried out subsequent to Case 5). The breakthrough time of $\mathrm{CO}_{2}$ is lower than that of Case 4 due to the initial loading of $\mathrm{H}_{2} \mathrm{O}$. However, the adsorbent still holds adsorption capacity toward $\mathrm{CO}_{2}$. It is important to highlight that again, the IASbased simulation describes the $\mathrm{CO}_{2}$ breakthrough curve better than the pure component model. On the other hand, the IASbased simulation predicts larger rollup in the $\mathrm{H}_{2} \mathrm{O}$ curve, because of the adsorption of $\mathrm{CO}_{2}$, than that observed experimentally (i.e., IAS slightly overestimates the effect of $\mathrm{CO}_{2}$ on $\mathrm{H}_{2} \mathrm{O}$ adsorption). At equilibrium, the IAS-based 
simulation predicts a reduction in the adsorption capacity, compared to the pure component adsorption models of 55\% for $\mathrm{N}_{2}, 23 \%$ for $\mathrm{CO}_{2}$, and $15 \%$ for $\mathrm{H}_{2} \mathrm{O}$, which is significantly below the reductions of Case 3 for $\mathrm{N}_{2}$ and $\mathrm{CO}_{2}$, because of the lower loading of $\mathrm{H}_{2} \mathrm{O}$ at $t=0$ in Case 6, given the lower relative humidity of the gas phase $(\mathrm{RH} \approx 23 \%)$.

Figure 9 summarizes the results for Case 7: a ternary breakthrough curve carried out over the adsorbent initially

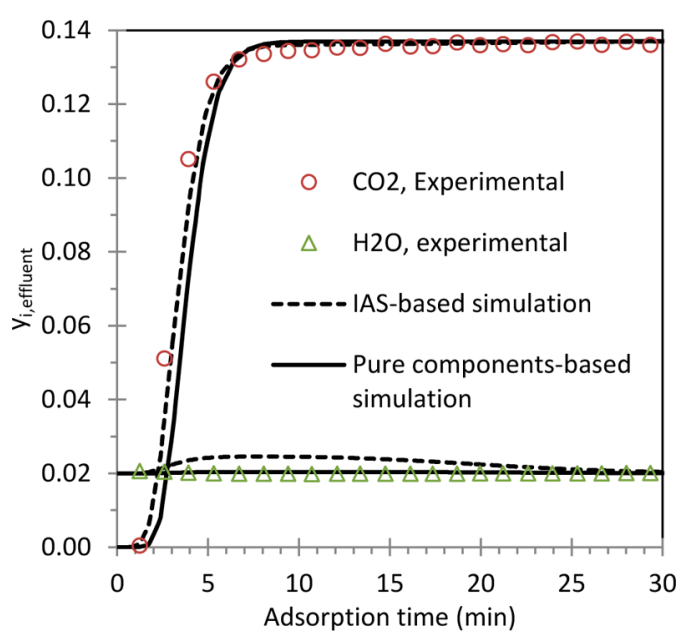

Figure 9. Case 7: breakthrough curve of a ternary mixture with $84 \%$ $\mathrm{N}_{2}, 14 \% \mathrm{CO}_{2}$, and $2 \% \mathrm{H}_{2} \mathrm{O}$ at $140 \mathrm{kPa}$ and $70{ }^{\circ} \mathrm{C}$, over the adsorbent in equilibrium with $98 \% \mathrm{~N}_{2}$ and $2 \% \mathrm{H}_{2} \mathrm{O}$ at $t=0$. The symbols represent the experimental data, the solid lines represent the results obtained by simulation using the pure component adsorption models, and the dashed lines represent the results obtained by simulation making use of the IAS theory.

saturated with $2 \% \mathrm{H}_{2} \mathrm{O}$ and $98 \% \mathrm{~N}_{2}$ at $70{ }^{\circ} \mathrm{C}$ (the relative humidity in the adsorber at $t=0$ was $9 \%$ ). Once again, IAS adequately represents the adsorption of $\mathrm{CO}_{2}$ in the presence of $\mathrm{H}_{2} \mathrm{O}$, although it slightly overestimates the influence of $\mathrm{CO}_{2}$ on $\mathrm{H}_{2} \mathrm{O}$ adsorption, which might be related to the nonideality of $\mathrm{H}_{2} \mathrm{O}$. The plot of the cumulative adsorbed amount versus time for Case 7 can be found in the Supporting Information. At equilibrium, IAS predicts similar adsorption capacity for $\mathrm{CO}_{2}$ and $\mathrm{H}_{2} \mathrm{O}: 0.36 \mathrm{mmol} \mathrm{g}^{-1}$, which represents a reduction of $13 \%$, compared to the pure component model for $\mathrm{CO}_{2}$, and $22 \%$, for $\mathrm{H}_{2} \mathrm{O} . \mathrm{N}_{2}$, which is the weakest adsorbate, presents the highest reduction: $37 \%$. Note that the reduction in the amounts of $\mathrm{CO}_{2}$ and $\mathrm{N}_{2}$ adsorbed, compared to the pure component models, are considerably lower than those of Cases 3 and 6, which were carried out at higher relative humidity.

In summary, the fixed-bed adsorption model based on IAS theory to predict multicomponent adsorption equilibrium satisfactorily describes the dynamic adsorption of $\mathrm{CO}_{2}$ in the presence of $\mathrm{N}_{2}$ and $\mathrm{H}_{2} \mathrm{O}$ over the wide range of operating conditions evaluated (from $23{ }^{\circ} \mathrm{C}$ to $70{ }^{\circ} \mathrm{C}$ and from $9 \% \mathrm{RH}$ to $95 \% \mathrm{RH})$. However, IAS theory has a tendency to slightly overestimate the influence of $\mathrm{CO}_{2}$ on $\mathrm{H}_{2} \mathrm{O}$ adsorption. According to the experimental data, $\mathrm{H}_{2} \mathrm{O}$ adsorption is hardly affected by $\mathrm{CO}_{2}$ adsorption.

Figure 10 shows the influence of temperature in the equilibrium adsorption capacity of the biochar calculated using the pure component models and also the IAS theory for a ternary mixture with $2 \% \mathrm{H}_{2} \mathrm{O}, 14 \% \mathrm{CO}_{2}$, and $84 \% \mathrm{~N}_{2}$ at $140 \mathrm{kPa}$. Note that the total amount adsorbed always decreases

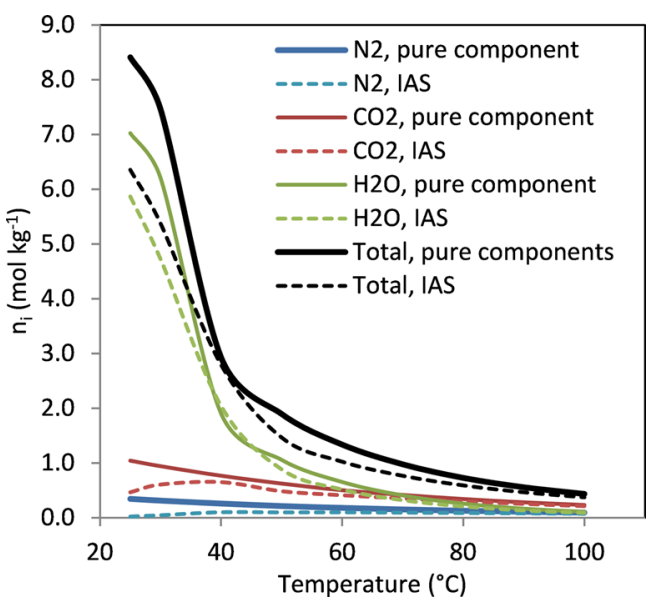

Figure 10. Effect of adsorption temperature on the biochar adsorption capacity for a ternary mixture with $2 \% \mathrm{H}_{2} \mathrm{O}, 14 \% \mathrm{CO}_{2}$, and $84 \% \mathrm{~N}_{2}$ at $140 \mathrm{kPa}$.

with increasing temperature, but this is not necessarily true for the individual components when competitive adsorption is considered. For example, for the case evaluated in Figure 10, the adsorption capacity predicted by IAS for $\mathrm{CO}_{2}$ increases slightly with temperature, going through a maximum at $40{ }^{\circ} \mathrm{C}$, because of the sharp reduction in the amount of $\mathrm{H}_{2} \mathrm{O}$ coadsorbed as the relative humidity decreases. The difference between the adsorption capacity of $\mathrm{CO}_{2}$ predicted by IAS and that expected for the pure component model reaches its maximum at the highest relative humidity evaluated.

\section{CONCLUSIONS}

The adsorption isotherms of $\mathrm{H}_{2} \mathrm{O}$ on a microporous biochar developed from olive stones were measured up to the corresponding saturation pressure in a static adsorption apparatus at 30,50 , and $70{ }^{\circ} \mathrm{C}$ to obtain high-quality data for the equilibrium of adsorption of pure $\mathrm{H}_{2} \mathrm{O}$ in a temperature and pressure range of interest for postcombustion $\mathrm{CO}_{2}$ capture applications. The maximum equilibrium adsorption capacity of the pure components follows the order $\mathrm{H}_{2} \mathrm{O}>\mathrm{CO}_{2}>\mathrm{N}_{2}$, as does the isosteric heat of adsorption, which presents typical values for carbon adsorbents, with average values of $45 \mathrm{~kJ} \mathrm{~mol}^{-1}$ for $\mathrm{H}_{2} \mathrm{O}, 29 \mathrm{~kJ} \mathrm{~mol}^{-1}$ for $\mathrm{CO}_{2}$, and $20 \mathrm{~kJ} \mathrm{~mol}^{-1}$ for $\mathrm{N}_{2}$. However, the microporous biochar evaluated in the present work presents a relatively low adsorption capacity for $\mathrm{H}_{2} \mathrm{O}$, compared to other adsorbents with higher pore volumes, especially at low relative pressures, which is advantageous from the point of view of its application in postcombustion $\mathrm{CO}_{2}$ capture. The equilibrium of adsorption of $\mathrm{H}_{2} \mathrm{O}$ was modeled using a temperature-dependent form of the extended CCMS model proposed by Rutherford. The IAS theory was used to model the equilibrium of adsorption of binary mixtures of $\mathrm{H}_{2} \mathrm{O}$ and $\mathrm{N}_{2}$ and ternary mixtures of $\mathrm{CO}_{2}, \mathrm{~N}_{2}$, and $\mathrm{H}_{2} \mathrm{O}$, based on the pure component adsorption models.

The dynamic experiments carried out using ternary mixtures of $\mathrm{CO}_{2}, \mathrm{~N}_{2}$, and $\mathrm{H}_{2} \mathrm{O}$ over a fully regenerated adsorbent bed (free of $\mathrm{CO}_{2}$ and $\mathrm{H}_{2} \mathrm{O}$ at $t=0$ ) show no reduction in the breakthrough time for $\mathrm{CO}_{2}$, compared to the dry cases evaluated in Part $1 .{ }^{19}$ However, a small rollup can be observed in the $\mathrm{CO}_{2}$ curves as a consequence of $\mathrm{H}_{2} \mathrm{O}$ adsorption.

The shape of the breakthrough curve of $\mathrm{H}_{2} \mathrm{O}$ is strongly dependent on the relative humidity of the feed gas: when the relative humidity is high, two uptake zones with an intermediate 
plateau are observed, that correspond to the shape of the equilibrium adsorption isotherm up to the saturation pressure; however, when the relative humidity of the feed is low, the breakthrough curve of $\mathrm{H}_{2} \mathrm{O}$ shows a single uptake zone with a steep breakthrough, typical for favorable equilibrium, which corresponds to the first stage of the adsorption isotherm.

The breakthrough curves carried out with ternary mixtures of $\mathrm{N}_{2}, \mathrm{CO}_{2}$, and $\mathrm{H}_{2} \mathrm{O}$ over the adsorbent initially saturated with $\mathrm{H}_{2} \mathrm{O}$ confirmed that $\mathrm{H}_{2} \mathrm{O}$ adsorption is little influenced by the adsorption of $\mathrm{CO}_{2}$ and that the adsorption capacity of $\mathrm{CO}_{2}$ is reduced by the amount of $\mathrm{H}_{2} \mathrm{O}$ initially adsorbed on the carbon, which, in turn, is strongly influenced by the relative humidity of the feed gas. A reduction in the $\mathrm{CO}_{2}$ adsorption capacity up to $64 \%$ can be expected for a relative humidity in the gas feed of $95 \%$. Therefore, the effect of competitive adsorption on $\mathrm{CO}_{2}$ capture should be considered within the adsorption model used for process design.

The fixed-bed adsorption model based on the IAS theory to predict multicomponent equilibrium is shown to be a powerful tool to describe the dynamic adsorption of $\mathrm{CO}_{2}$ in the presence of $\mathrm{H}_{2} \mathrm{O}$ and $\mathrm{N}_{2}$ in the wide range of scenarios considered in the present work: from adsorption over a fully regenerated adsorbent bed (best scenario evaluated), to adsorption over an adsorbent bed initially saturated with $\mathrm{H}_{2} \mathrm{O}$ at high relative humidity, which represents the worst-case scenario. Therefore, it represents a useful tool for $\mathrm{CO}_{2}$ capture process design.

\section{ASSOCIATED CONTENT}

\section{S Supporting Information}

The Supporting Information is available free of charge on the ACS Publications website at DOI: 10.1021/acs.iecr.6b01720.

Transient response of the fixed-bed adsorption unit to a step change in the feed composition (blank breakthrough experiment); sensitivity analysis on the effect of the mass transfer coefficient of $\mathrm{H}_{2} \mathrm{O}$ for Case 2; plots for the cumulative amount of $\mathrm{N}_{2}, \mathrm{CO}_{2}$ and $\mathrm{H}_{2} \mathrm{O}$ adsorbed versus time for Cases 2-7; breakthrough curve of $\mathrm{H}_{2} \mathrm{O}$ for Case 5 ; summary of the equations, initial conditions, and nomenclature of the dynamic fixed-bed adsorption model used to run the simulations of the breakthrough experiments (PDF)

\section{AUTHOR INFORMATION}

\section{Corresponding Author}

*E-mail: cpevida@incar.csic.es.

\section{Author Contributions}

The manuscript was written through contributions of all authors. All authors have given approval to the final version of the manuscript.

\section{Funding}

Work carried out with financial support from the HiPerCap Project of the European Union 7th Framework Programme (FP7) (2007-2013; Grant Agreement No. 60855).

\section{Notes}

The authors declare no competing financial interest.

\section{ACKNOWLEDGMENTS}

M.G.P. acknowledges funding from the CSIC (JAE-Doc program cofinanced by the European Social Fund). N.Q. acknowledges funding from the Government of the Principado de Asturias (Severo Ochoa program). Authors also appreciate the support from the technical consultants of Aspen Technology Inc., M.M. and E.L.

\section{ABBREVIATIONS}

$\mathrm{CEM}=$ controlled evaporator mixer

CMMS = cooperative multimolecular sorption

$\mathrm{DJD}=$ model for the adsorption and desorption of $\mathrm{H}_{2} \mathrm{O}$

proposed by Do Junpirom, and Do

IAS = ideal adsorption solution

LDS = liquid delivery system

MSE = mean squared error

$\mathrm{RH}=$ relative humidity

STP $=$ standard temperature and pressure $\left(0{ }^{\circ} \mathrm{C}\right.$ and 0.1 $\mathrm{MPa})$

\section{NOMENCLATURE}

$b_{\mathrm{L}}=$ Langmuir affinity constant for the interaction of water with the surface functional groups $\left(\mathrm{kPa}^{-1}\right)$

$D_{\mathrm{e}}=$ effective diffusivity $\left(\mathrm{m}^{2} \mathrm{~s}^{-1}\right)$

HTC = heat-transfer coefficient between the gas and the adsorbent particles $\left(\mathrm{W} \mathrm{m}{ }^{-2} \mathrm{~K}^{-1}\right)$

$h_{\mathrm{w}}=$ heat-transfer coefficient between the gas and the adsorber wall $\left(\mathrm{W} \mathrm{m}^{-2} \mathrm{~K}^{-1}\right)$

$H_{\text {amb }}=$ heat-transfer coefficient between the outer wall of the adsorber and the environment $\left(\mathrm{W} \mathrm{m}{ }^{-2} \mathrm{~K}^{-1}\right)$

$K_{0}=$ equilibrium constant for the adsorption on the primary site $\left(\mathrm{kPa}^{-1}\right)$

$K_{1}=$ equilibrium constant of adsorption on the side unit of the primary site $\left(\mathrm{kPa}^{-1}\right)$

$n_{\mathrm{L}}=$ maximum adsorption capacity on the surface functional groups $\left(\mathrm{mmol} \mathrm{g}^{-1}\right)$

$n_{\mathrm{s}}=$ saturation capacity for the adsorption of water in the micropores $\left(\mathrm{mmol} \mathrm{g}^{-1}\right)$

$n_{\mathrm{H}_{2} \mathrm{O}}=$ total amount of $\mathrm{H}_{2} \mathrm{O}$ adsorbed $\left(\mathrm{mmol} \mathrm{g}^{-1}\right)$

MTC = mass-transfer coefficient $\left(\mathrm{s}^{-1}\right)$

$P=$ pressure $(\mathrm{kPa})$

$q_{\mathrm{L}}=$ parameter of the extended CMMS model related to the enthalpy of adsorption on the surface functional groups (J $\mathrm{mol}^{-1}$ )

$q_{0}=$ parameter of the extended CMMS model related to the enthalpy of adsorption on the primary sites $\left(\mathrm{J} \mathrm{mol}^{-1}\right)$

$q_{1}=$ parameter of the extended CMMS model related to the enthalpy of adsorption on the side units of the primary sites $\left(\mathrm{J} \mathrm{mol}^{-1}\right)$

$\mathrm{R}=$ universal gas constant; $\mathrm{R}=8.31 \mathrm{~J} \mathrm{~mol}^{-1} \mathrm{~K}^{-1}$

$R_{\mathrm{p}}=$ particle radius $(\mathrm{m})$

$t=$ time $(\mathrm{min})$

$T=$ temperature $(\mathrm{K})$

$T_{\text {ref }}=$ reference temperature $(303 \mathrm{~K})$

$w_{\text {Ising }}=$ Ising isotherm (eq 2)

\section{REFERENCES}

(1) Shen, C. M.; Worek, W. M. Cosorption characteristics of solid adsorbents. Int. J. Heat Mass Transfer 1994, 37, 2123-2129.

(2) Rege, S. U.; Yang, R. T. A novel FTIR method for studying mixed gas adsorption at low concentrations: $\mathrm{H}_{2} \mathrm{O}$ and $\mathrm{CO}_{2}$ on $\mathrm{NaX}$ zeolite and $\gamma$-alumina. Chem. Eng. Sci. 2001, 56, 3781-3796.

(3) Bai, R.; Yang, R. T. A Modification of the Doong-Yang Model for Gas Mixture Adsorption Using the Lewis Relationship. Langmuir 2005, 21, 8326-8332.

(4) Sjostrom, S.; Krutka, H. Evaluation of solid sorbents as a retrofit technology for $\mathrm{CO}_{2}$ capture. Fuel 2010, 89, 1298-1306. 
(5) Ishibashi, M.; Ota, H.; Akutsu, N.; Umeda, S.; Tajika, M.; Izumi, J.; Yasutake, A.; Kabata, T.; Kageyama, Y. Technology for removing carbon dioxide from power plant flue gas by the physical adsorption method. Energy Convers. Manage. 1996, 37, 929-933.

(6) Wang, L.; Yang, Y.; Shen, W.; Kong, X.; Li, P.; Yu, J.; Rodrigues, A. E. Experimental evaluation of adsorption technology for $\mathrm{CO}_{2}$ capture from flue gas in an existing coal-fired power plant. Chem. Eng. Sci. 2013, 101, 615-619.

(7) Majchrzak-Kuçeba, I. VPSA adsorption technology for $\mathrm{CO}_{2}$ capture from power plant. Presented at The Seventh International Conference on Clean Coal Technologies (CCT2015), Kraków, Poland, May17-21, 2015.

(8) Li, G.; Xiao, P.; Webley, P.; Zhang, J.; Singh, R.; Marshall, M. Capture of $\mathrm{CO}_{2}$ from high humidity flue gas by vacuum swing adsorption with zeolite 13X. Adsorption 2008, 14, 415-422.

(9) Jin, Z.; Firoozabadi, A. Effect of water on methane and carbon dioxide sorption in clay minerals by Monte Carlo simulations. Fluid Phase Equilib. 2014, 382, 10-20.

(10) Rutherford, S. W. Probing the Mechanism of Water Adsorption in Carbon Micropores with Multitemperature Isotherms and Water Preadsorption Experiments. Langmuir 2006, 22, 9967-9975.

(11) Xu, D.; Xiao, P.; Zhang, J.; Li, G.; Xiao, G.; Webley, P. A.; Zhai, Y. Effects of water vapour on $\mathrm{CO}_{2}$ capture with vacuum swing adsorption using activated carbon. Chem. Eng. J. (Amsterdam, Neth.) 2013, 230, 64-72.

(12) Malakhov, A. O.; Volkov, V. V. Cooperative multimolecular sorption equation: Application to an alcohol-poly(1-trimethylsilyl-1propyne) system. Polym. Sci., Ser. A 2000, 40, 1120-1126.

(13) Rutherford, S. W. Modeling water adsorption in carbon micropores: Study of water in carbon molecular sieves. Langmuir 2006, 22, 702-708.

(14) Plaza, M. G.; González, A. S.; Rubiera, F.; Pevida, C. Water vapour adsorption by a coffee-based microporous carbon: Effect on $\mathrm{CO}_{2}$ capture. J. Chem. Technol. Biotechnol. 2015, 90, 1592-1600.

(15) Plaza, M. G.; González, A. S.; Pevida, C.; Rubiera, F. Influence of water vapor on $\mathrm{CO}_{2}$ adsorption using a biomass-based carbon. Ind. Eng. Chem. Res. 2014, 53, 15488-15499.

(16) Plaza, M. G.; González, A. S.; Rubiera, F.; Pevida, C. Evaluation of Microporous Biochars Produced by Single-Step Oxidation for Postcombustion $\mathrm{CO}_{2}$ Capture under Humid Conditions. Energy Procedia 2014, 63, 693-702.

(17) Ruthven, D. M. Principles of Adsorption and Adsorption Processes; John Wiley and Sons: New York, 1984.

(18) AspenTech. Aspen Adsorption V8.0 Guide, 2012.

(19) Plaza, M. G.; Durán, I.; Querejeta, N.; Rubiera, F.; Pevida, C. Experimental and Simulation Study of Adsorption in Postcombustion Conditions Using a Microporous Biochar. 1. $\mathrm{CO}_{2}$ and $\mathrm{N}_{2}$ Adsorption. Ind. Eng. Chem. Res. 2016, 55, 3097-3112.

(20) Myers, A. L.; Prausnitz, J. M. Thermodynamics of mixed-gas adsorption. AIChE J. 1965, 11, 121-127.

(21) Plaza, M. G.; González, A. S.; Pis, J. J.; Rubiera, F.; Pevida, C. Production of microporous biochars by single-step oxidation: Effect of activation conditions on $\mathrm{CO}_{2}$ capture. Appl. Energy 2014, 114, 551562.

(22) Do, D. D.; Junpirom, S.; Do, H. D. A new adsorptiondesorption model for water adsorption in activated carbon. Carbon 2009, 47, 1466-1473.

(23) Horikawa, T.; Sekida, T.; Hayashi, J. i.; Katoh, M.; Do, D. D. A new adsorption-desorption model for water adsorption in porous carbons. Carbon 2011, 49, 416-424.

(24) Harding, A. W.; Foley, N. J.; Norman, P. R.; Francis, D. C.; Thomas, K. M. Diffusion Barriers in the Kinetics of Water Vapor Adsorption/Desorption on Activated Carbons. Langmuir 1998, 14, $3858-3864$.

(25) Cossarutto, L.; Zimny, T.; Kaczmarczyk, J.; Siemieniewska, T.; Bimer, J.; Weber, J. V. Transport and sorption of water vapour in activated carbons. Carbon 2001, 39, 2339-2346.
(26) Ryu, Y.; Lee, S.; Kim, J.; Leef, C.-H. Adsorption equilibrium and kinetics of $\mathrm{H}_{2} \mathrm{O}$ on zeolite 13X. Korean J. Chem. Eng. 2001, 18, 525530.

(27) Qi, S.; Hay, K.; Rood, M.; Cal, M. Equilibrium and heat of adsorption for water vapor and activated carbon. J. Environ. Eng. (Reston, VA, U.S.) 2000, 126, 267-271.

(28) Rudisill, E. N.; Hacskaylo, J. J.; LeVan, M. D. Coadsorption of hydrocarbons and water on BPL activated carbon. Ind. Eng. Chem. Res. 1992, 31, 1122-1130.

(29) Wang, Y.; LeVan, M. D. Adsorption Equilibrium of Carbon Dioxide and Water Vapor on Zeolites 5A and 13X and Silica Gel: Pure Components. J. Chem. Eng. Data 2009, 54, 2839-2844.

(30) Do, D. D.; Do, H. D. A model for water adsorption in activated carbon. Carbon 2000, 38, 767-773.

(31) Tsunoda, R; Ando, J-i. Adsorption of water vapor on active carbons: Estimation of the average pore width from the magnitude of the hysteresis loop. J. Colloid Interface Sci. 1991, 146, 291-293.

(32) Perry, R. H.; Green, D. W. Perry's Chemical Engineers' Handbook, 7th Edition; McGraw-Hill: New York, 1997.

(33) Cortés, F. B.; Chejne, F.; Carrasco-Marín, F.; Moreno-Castilla, C.; Pérez-Cadenas, A. F. Water adsorption on zeolite 13X: Comparison of the two methods based on mass spectrometry and thermogravimetry. Adsorption 2010, 16, 141-146.

(34) Dubinin, M. M.; Vartapetian, R. S.; Voloshchuk, A. M.; Kärger, J.; Pfeifer, H. NMR study of translational mobility of molecules adsorbed on active carbons. Carbon 1988, 26, 515-520.

(35) Gilliland, E. R.; Baddour, R. F.; Perkinson, G. P.; Sladek, K. J. Diffusion on Surfaces. I. Effect of Concentration on the Diffusivity of Physically Adsorbed Gases. Ind. Eng. Chem. Fundam. 1974, 13, 95100. 